\title{
Solid-State Molecular Folding and Supramolecular Structures of Triptycene-Derived Secondary Dicarboxamides
}

\author{
J ye-Shane Yang, ${ }^{\dagger, *}$ Chia-Peng Liu, ${ }^{\dagger}$ Bor-Ching Lin, ${ }^{\dagger}$ Chih-Wei Tu, ${ }^{\dagger}$ and Gene-Hsiang Lee ${ }^{\ddagger}$ \\ Department of Chemistry, National Central University, Chung-Li 32054, \\ Taiwan and Instrumentation Center, National Taiwan University, Taipei 10660, Taiwan
}

jsyang@cc.ncu.edu.tw

Received March 25, 2002

\begin{abstract}
The synthesis and X-ray crystal structures of triptycene-derived secondary dicarboxamides $\mathbf{1}$ and 4-7 and reference compounds 2, 3, and $\mathbf{8}$ are reported. For comparison, molecular conformations of 1-8 in the gas phase and those of $\mathbf{1}$ and $\mathbf{3}-\mathbf{6}$ in $\mathrm{CD}_{2} \mathrm{Cl}_{2}$ investigated by $\mathrm{AM} 1$ modeling and ${ }^{\mathrm{H}} \mathrm{H}$ NMR spectroscopy, respectively, are also included. The solid-state conformations of $\mathbf{1}$ and $\mathbf{5 - \mathbf { 8 }}$ are fol ded and compact, resulting from the cooperative effects of intramolecular amide-amide hydrogen bonding and edge-to-face arene-arene interactions between the triptycene and the $\mathrm{N}$-acetylsulfanilyl groups. The sulfonyl ester groups are also essential in the folding of $\mathbf{1}$ and 5-8 and function as structural turn units. In contrast, the conformations of 2-4 are unfolded due to the lack of one of these three essentials. The extended triptycene ring systems in $\mathbf{6}$ and $\mathbf{7}$ provide an arene-arene contact mode that is different from that for $\mathbf{1}$ and $\mathbf{5}$. While AM 1 calculations suggest that the two possible arene-arene contact modes in $\mathbf{6}$ and $\mathbf{7}$ have similar conformational energies, the one observed in the solid state is also favored in solutions. To achieve a more regular shape for compact crystal packing, the bulky triptycene groups tend to pack in pairs. As a result, the intermolecular amide-amide hydrogen bonding is perturbed and modified with the participation of either the sulfonyl groups or the methanol solvent molecules, leading to various hydrogen-bonding motifs for these triptycene diamides.
\end{abstract}

\section{Introduction}

The phenomenon of molecular folding that leads to compact conformations in flexible molecules is a consequence of intramolecular recognition, which relies on specific noncovalent interactions. ${ }^{1}$ Important driving forces include the intrinsic conformational preferences of molecular backbone, hydrogen bonding, arene-arene interactions, polar interactions, and solvation (e.g., the solvophobic effect). Numerous efforts have been devoted toward a better understanding of these forces in protein folding, ${ }^{2}$ which has in turn offered a basis for the development of peptidomimetics ${ }^{3}$ and unnatural oligomers (foldamers) ${ }^{4}$ that mimic the secondary or tertiary

\footnotetext{
† Department of Chemistry, National Central University.

₹ Instrumentation Center, National Taiwan University.

(1) (a) Gellman, S. H. Chem. Rev. 1997, 97, 1231-1232. (b) MüllerDethlefs, K.; Hobza, P. Chem. Rev. 2000, 100, 143-167.

(2) (a) Glusker, J. P. The Crystal as a Supramolecular EntityPerspectives in Supramolecular Chemistry; Desiraju, G. R. Ed. J ohn Wiley \& Sons: Chichester, 1996; Vol. 2, Chapter 6. (b) Robertson, A D.; Murphy, K. P. Chem. Rev. 1997, 97, 1251-1268. (c) Nakhle, B. M.; Silinski, P.; Fitzgerald, M. C. J . Am. Chem. Soc. 2000, 122, 81058111. (d) Syud, F. A.; Stanger, H. E.; Gellman, S. H. J . Am. Chem. Soc. 2001, 123, 8667-8677. (e) Venkatraman, J.; Shankaramma, S. C.; Balaram, P. Chem. Rev. 2001, 101, 3131-3152.

(3) (a) Nowick, J. S. Acc. Chem. Res. 1999, 32, 287-296. (b) Nowick, J. S.; Chung, D. M.; Maitra, K.; Maitra, S.; Stigers, K. D.; Sun, Y.J. Am. Chem. Soc. 2000, 122, 7654-7661. (c) Smith, A. B. III; Wang, W.; Sprengeler, P. A.; Hirschmann, R. J . Am. Chem. Soc. 2000, 122 11037-11038. (d) Cheng, R. P.; Gellman, S. H.; DeGrado, W. F. Chem. Rev. 2001, 101, 3219-3232.

(4) Hill, D. J.; Mio, M.J.; Prince, R. B.; Hughes, T. S.; Moore, J . S. Chem. Rev. 2001, 101, 3893-4011.
}

protein structures and functionalities. In this context, fundamental studies by elucidating the essential structural elements and noncovalent interactions on the fol ding of small organic molecules have provided important contributions. ${ }^{5}$

The issue of folding vs unfol ding is also important for flexible building blocks in the construction of solid-state supramolecular architectures, given their distinct differences in both the shape and functionalities for intermolecular connections. In addition, a folded building block can be unfolded or vice versa as a result of minor structural modifications. A recent example was provided by Moore et al. with a series of well-defined oligo(mphenylene ethynylene)s, where the introduction of methyl substituents into the aromatic backbone causes the sol idstate structures to change from a lamellar organization of extended chains to a hexagonal arrangement of helical columns. ${ }^{6}$ Apparently, even the small nonfunctional methyl groups can significantly perturb the interplay between intra- and intermolecular noncovalent interac-

(5) F or recent examples, see: (a) Gung, B. W.; Zhu, Z. J . Org. Chem. 1996, 61, 6482-6483. (b) Gung, B, W.; Zhu, Z. J . Org. Chem. 1997, 62, 2324-2325. (c) J unquera, E.; N owick, J. S. J . Org. Chem. 1999, 64, 2527-2531. (d) Corbin, P. S.; Zimmerman, S. C.J . Am. Chem. Soc. 2000, 122, 3779-3780. (e) Huck, B. R.; Fisk, J . D.; Gellman, S. H. Org Lett. 2000, 2, 2607-2610. (f) Schmuck, C. J. Org. Chem. 2000, 65, 2432-2437. (g) Langenhan, J . M.; Fisk, J . D.; Gellman, S. H. Org. Lett. 2001, 3, 2559-2562.

(6) (a) Prest, P.-J .; Prince, R. B.; Moore, J . S. J . Am. Chem. Soc 1999, 121, 5933-5939. (b) Mio, M. J .; Prince, R. B.; Moore, J. S. J. Am. Chem. Soc. 2000, 122, 6134-6135. 
(a)
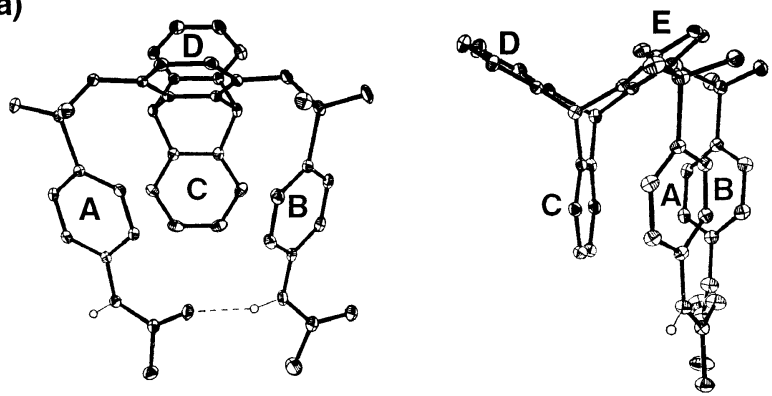

(b)

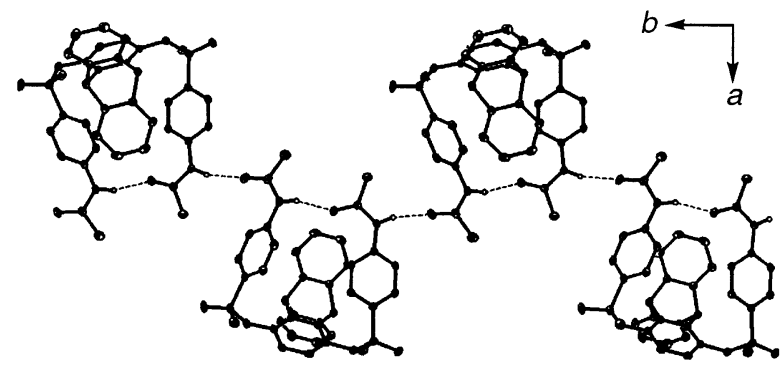

(c)

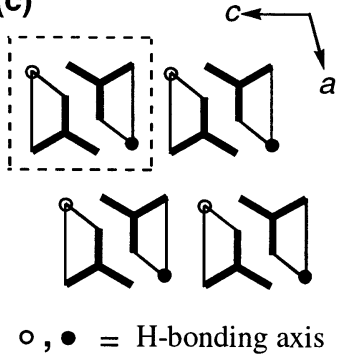

$1 \mathrm{~m}$

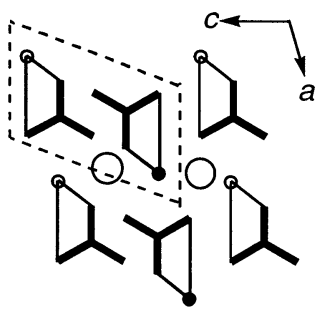

$\mathrm{O}=$ solvent channel

$1 \mathrm{mt}$

FIGURE 1. Crystal structure of 1: (a) two views of the molecular conformation in $\mathbf{1 m}$ with labels on the benzene rings, (b) a hydrogen-bonding chain in $\mathbf{1 m}$, and (c) a schematic representation of the crystal packing looking down the hydrogen-bonding axis (b direction, void and solid circles indicate the upward $\mathrm{NH}$ and $\mathrm{CO}$ side of the amide groups, respectively) showing the triptycene-triptycene alignments (bold lines) and supramolecular duplex (indicated by a dashed box, see text for definition) in both $\mathbf{l m}$ and $\mathbf{l m t}$.

tions in the solid state. Thus, an investigation of structural effects will not only furnish further insights into the solid-state noncovalent interactions but al so allow the evaluation of the folding propensity of target systems.

We recently reported that the triptycene-derived secondary dicarboxamide $\mathbf{1}$ is folded in the solid state, forming a 21-membered ring involving intramolecular hydrogen bond and edge-to-face arene-arene contacts between the triptycene and the $\mathrm{N}$-acetylsulfanilyl groups (Figure 1a). ${ }^{7}$ Such a compact conformation as well as the resulting one-dimensional hydrogen-bonding chain motif (Figure 1b) appears to be independent of the solvents used for crystallization. ${ }^{8}$ In addition, the triptycene moieties between adjacent chains pack in pairs (Figure

(7) Yang, J .-S.; Liu, C.-P.; Lee, G.-H. Tetrahedron Lett. 2000, 41, $7911-7915$

(8) In addition to methanol and toluene, ${ }^{7}$ DMSO does not interrupt the folded conformation and hydrogen-bonding chain motif either, because the crystals from a mixed methanol-DMSO solution were determined to have the same structure as $\mathbf{I m}$ (data not shown).

1c). Although "isomeric" crystals ${ }^{9}$ are formed for $\mathbf{1}$ from methanol vs methanol-toluene mixed solutions, all the above-mentioned structural features are displayed in both crystals. To identify the driving forces responsible for the compact folding of $\mathbf{1}$ and to investigate how structural modifications of $\mathbf{1}$ affect the molecular conformation and supramolecular structure, we have designed and synthesized compounds 2-8 (Chart 1). When compared with $\mathbf{1}$, compounds $\mathbf{2}$ and $\mathbf{3}$ lack the amide groups for intramolecular hydrogen bonding and the flanking triptycene benzene rings for arene-arene interactions, ${ }^{10}$ respectively. It has been suggested that sulfonyl esters (sulfonates) are conformationally more flexible than carbonyl esters with a corresponding preference of gauche vs planar s-trans (Z) conformation. ${ }^{11}$ Thus, the contribution of sulfonyl ester groups as being turn elements to the folding of $\mathbf{1}$ could be validated when compared with its carbonyl ester analogue 4. Compounds 5-7 are the results of structural modifications to the amide or triptycene moieties of $\mathbf{1}$. The investigation of compound $\mathbf{8}$ is for the comparison with $\mathbf{6}$ due to the observation of an alternative arene-arene contact mode (vide infra). The X-ray crystal structures of $\mathbf{1 - 8}$ reported herein indicate that the intramolecular amide-amide hydrogen bonding, the arene-arene interactions, and the gauche sulfonyl ester groups are all essential for the folding of $\mathbf{1}$. Structural modifications of $\mathbf{1}$ without interfering with these three essentials preserve the molecular folding behavior. Moreover, the pairwise packing of the triptycene groups appears to take priority over the choice of intermolecular hydrogen bonding. The results of AM 1 modeling ${ }^{12}$ on the gas-phase mol ecular conformations of 1-8 and the ${ }^{1} \mathrm{H}$ NMR conformational studies on $\mathbf{1}$ and 3-6 in $\mathrm{CD}_{2} \mathrm{Cl}_{2}$ at 295 and $223 \mathrm{~K}$ are also included and compared with the observed solid-state conformations.

\section{Results and Discussion}

Synthesis. The triptycene derivatives 1, 2, 4, and $\mathbf{5}$ are all prepared from the same precursor $\mathbf{9}$ (Scheme $\mathbf{1}$ ). Triptycene hydroquinone $\mathbf{9}$ was synthesized according to the method of Bartlett starting with anthracene and benzoquinone. ${ }^{13}$ The reactions between 9 and the commercially available 4-acetamido-, 4-methyl-, and 4-nitrobenzenesulfonyl chlorides in refluxed acetone solutions with the presence of potassium carbonate as the base afford 1, 2, and 10, respectively. The same reaction condition was also employed to make $\mathbf{3}$ by replacing $\mathbf{9}$ with hydroquinone. The dinitro species $\mathbf{1 0}$ was reduced by $\operatorname{tin}(\mathrm{II})$ chloride to the diamine $\mathbf{1 1}$, which was then reacted with benzoyl chloride to provide $\mathbf{5}$. Compound $\mathbf{4}$ was obtained from the reaction of $\mathbf{9}$ and 4-acetamidobenzoic acid with DCC as the coupling agent and catalytic amounts of DMAP.

(9) Moulton, B.; Zaworotko M. J . Chem. Rev. 2001, 101, 1629-1658.

(10) (a) J ennings, W. B.; Farrell, B. M.; Malone, J . F. Acc. Chem. Res. 2001, 34, 885-894. (b) Tsuzuki, S.; Honda, K.; Uchimaru, T.; Mikami, M.; Tanabe, K.J . Am. Chem. Soc. 2002, 124, 104-112.

(11) (a) Exner, O.; Fidlerová, Z.; J ehlièka, V. Collect. Czech. Chem. Commun. 1968, 33, 2019-2028. (b) Trautner, F.; Altabef, A. B.; Fernandez, L. E.; Varetti, E. L.; Oberhammer, H. Inorg. Chem. 1999, 38, 3051-3055. (c) Cain, D.; Pawar, D. M.; Stewart, M.; Billings, H., J r.; Noe, E. A. J . Org. Chem. 2001, 66, 6092-6095.

(12) Dewar, M. J . S.; Zoebisch, E. G.; Healy, E. F.; Stewart, J J J . P J . Am. Chem. Soc. 1985, 107, 3902-3909.

(13) Bartlett, P. D.; Ryan, M. J .; Cohen, S. G. J . Am. Chem. Soc 1942, 64, 2649-2653. 


\section{CHART 1}

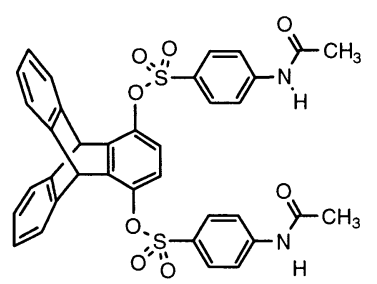

1

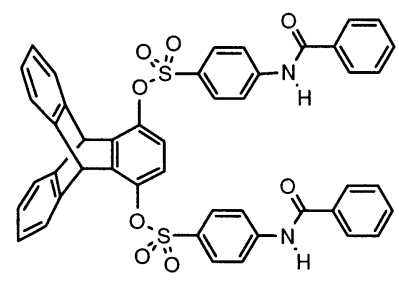

5

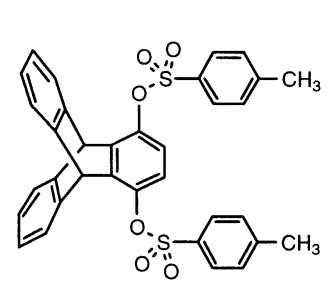

2<smiles>CC(=O)Nc1ccc(S(=O)(=O)Oc2ccc(OS(=O)(=O)c3ccc(NC(C)=O)cc3)cc2)cc1</smiles><smiles>CC(=O)Nc1ccc(COc2c(Oc3ccc(NC(C)=O)cc3)ccc3c2Oc2cccc(c2OCc2ccccc2)C3C2CC2)cc1</smiles>

3

4

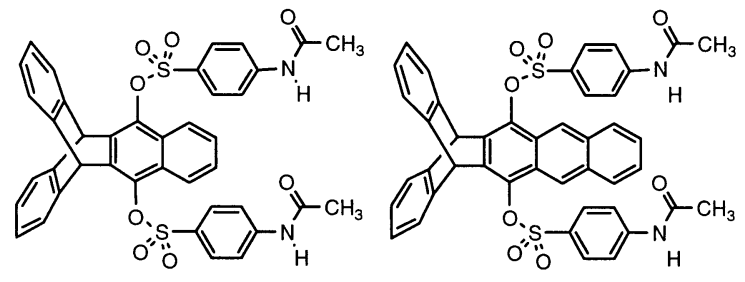

6

7

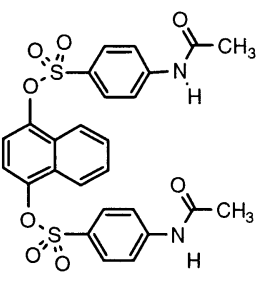

8

SCHEME 1

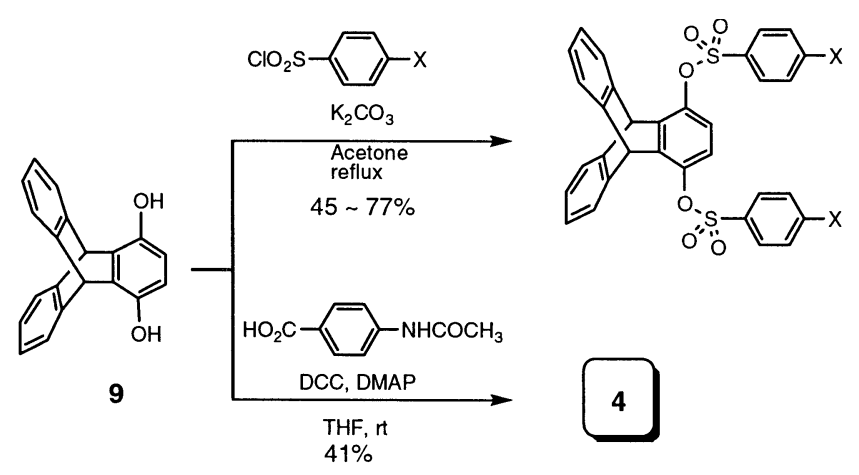

$1 \mathrm{X}=\mathrm{NHCOCH}_{3}$

$2 \mathrm{X}=\mathrm{CH}_{3}$

$10 \mathrm{X}=\mathrm{NO}_{2} \longrightarrow \mathrm{SnCl}_{2}, \mathrm{EtOH}, 75^{\circ} \mathrm{C}$

$11 \mathrm{X}=\mathrm{NH}_{2} \longleftarrow 80 \%$

$5 \mathrm{X}=\mathrm{NHCOPh} \longleftarrow \begin{aligned} & \text { Benzoyl chloride } \\ & \mathrm{NEt}_{3}, \mathrm{CH}_{2} \mathrm{Cl}_{2} \text {, it }\end{aligned}$

$65 \%$

\section{SCHEME 2}

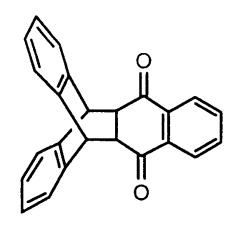

12

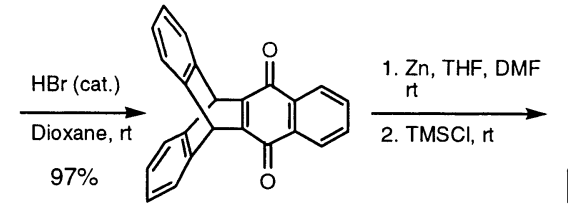

14

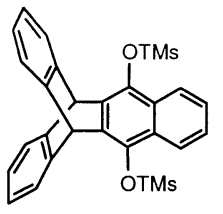

16

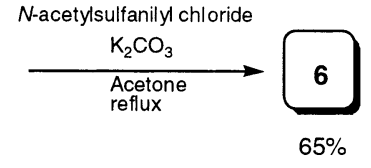

$65 \%$

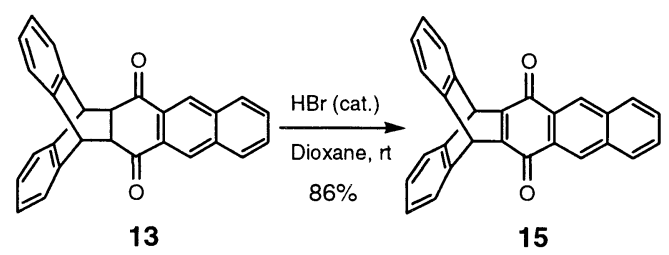

15

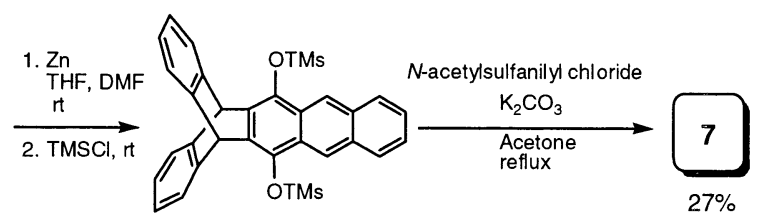

17
The synthesis of triptycene derivatives $\mathbf{6}$ and $\mathbf{7}$ is outlined in Scheme 2. In principle, the synthesis of $\mathbf{6}$ and 7 could be accomplished by following the same method for the preparation of $\mathbf{1}$ using the corresponding triptycene hydroquinones $\mathbf{1 9}$ and $\mathbf{2 0}$. However, due to the poor stability of $\mathbf{1 9}$ and $\mathbf{2 0}$ in the air, the trimethylsilyl
(TMS) group-protected species $\mathbf{1 6}$ and $\mathbf{1 7}$, generated from the reduction of the corresponding triptycene quinones $\mathbf{1 4}$ and 15, were used instead. Precursors $\mathbf{1 2}$ and $\mathbf{1 3}$ were prepared according to the method of Patney. ${ }^{14}$

Compound $\mathbf{8}$ was synthesized based on a two-step route starting with 1,4-naphthoquinone (Scheme 3). The method 
SCHEME 3
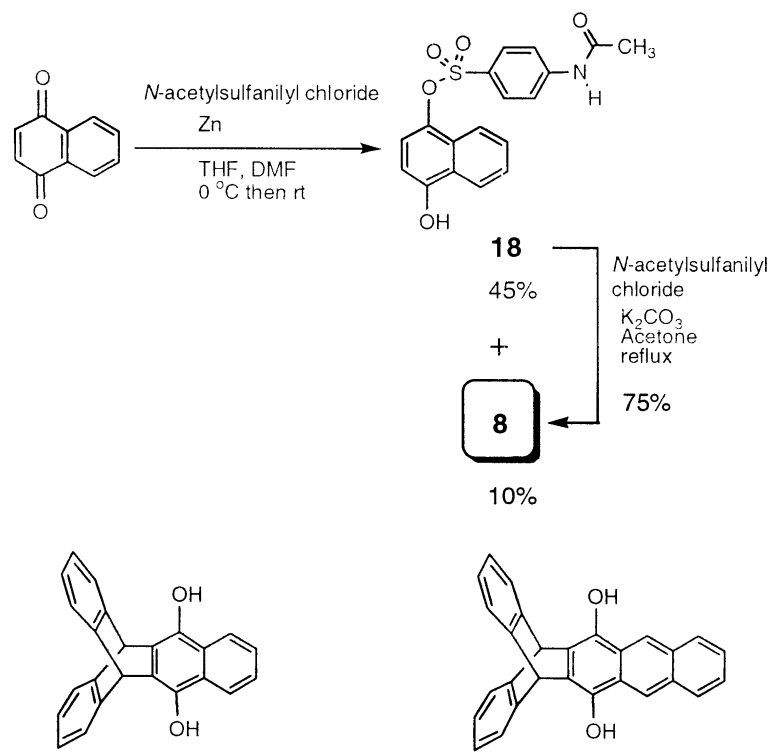

19

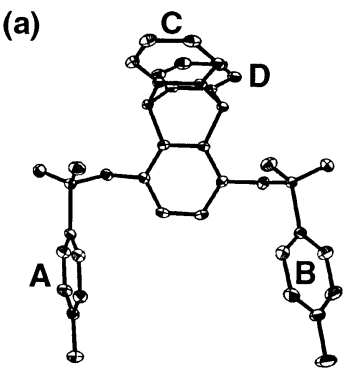

(b)

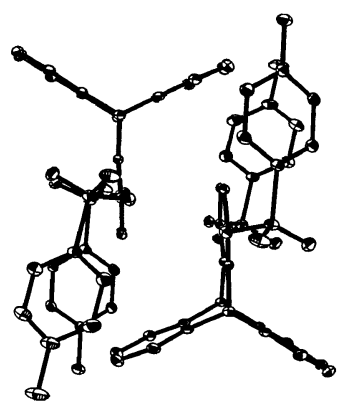

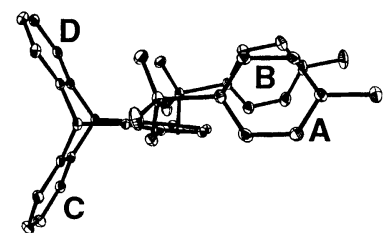

(c)

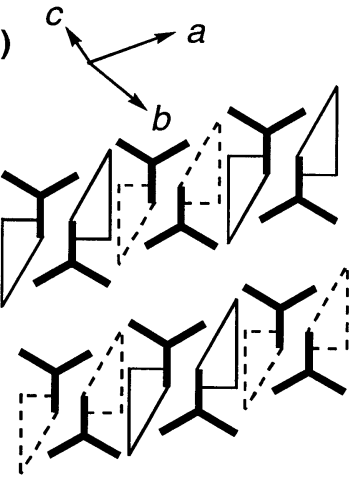

FIGURE 2. Crystal structure of 2: (a) two views of the molecular conformation with labels on the benzene rings, (b) a supramolecular dimer (see text for defineition), and (c) a schematic representation of the crystal packing showing the triptycene-triptycene alignments (bold lines) and adjacent supramol ecular dimers (drawings with dashed lines indicate a location of molecules in a lower plane).

On the basis of the crystal structures of 2-4, we conclude that the intramolecular amide-amide hydrogen bonding, the edge-to-face arene-arene interactions, and the sulfonyl ester turn units are all required for the folding of $\mathbf{1}$ in the solid state. The molecular structures of 5-8 further demonstrate that structural modifications of $\mathbf{1}$ without perturbing these three essentials will not affect the folding behavior. The results of $\mathbf{6}$ and $\mathbf{7}$ also reveal that not only the flanking benzene rings but also the extended aromatic backbone in the triptycene group allow for intramol ecular arene-arene interactions. This is further borne out by the persistent arene-arene contacts in $\mathbf{8}$, a derivative of $\mathbf{6}$ by removing the triptycene flanking benzene rings. The compact fol ding of $\mathbf{1}$ and 5-8 appear to be favorable, because the presence of hydrogenbond-active (e.g., $\mathrm{MeOH}$ and DMSO) ${ }^{8}$ and/or aromaticcontaining solvents (e.g., toluene) during the crystallization of them does not affect the intramolecular hydrogen bonding and arene-arene interactions, respectively.

The intramolecular geometric data of the three essentials responsible for the folding of $\mathbf{1}$ and 5-8 are reported in Table 1. The "idealized" geometry for secondary amide-amide hydrogen bonding includes a planar $\mathrm{N}-\mathrm{H} \cdots \mathrm{O}=\mathrm{C}$ system, a linear $\mathrm{N}-\mathrm{H} \cdots \mathrm{O}$ bond, and an angle of $\sim 120^{\circ}$ for $\mathrm{N}(\mathrm{H}) \cdots \mathrm{O}=\mathrm{C}$ (a direction toward the oxygen $\mathrm{sp}^{2}$ lone pairs). ${ }^{15}$ Among $\mathbf{1}$ and 5-8, the intramolecular hydrogen-bonding geometry in $\mathbf{5}$ is the least "ideal" and the only one that belongs to the category of "weak" hydrogen bonds. ${ }^{15 c}$ This could be attributed to the edge-to-face interactions between the $\mathrm{N}$-benzoyl groups,

(15) (a) Leiserowitz, L.; Tuval, M. Acta Crystallogr. 1978, B34, 1230-1247. (b) Taylor, R.; Kennard, O. Acc. Chem. Res. 1984, 17, 320326. (c) Steiner, T. Angew. Chem., Int. Ed. 2002, 41, 48-76 and references therein.

(14) (a) Patney, H. K.: Paddon-Row, M. N. Synthesis 1986, 326328. (b) Patney, H. K. Synthesis 1991, 694-696. 
(a)

(b)

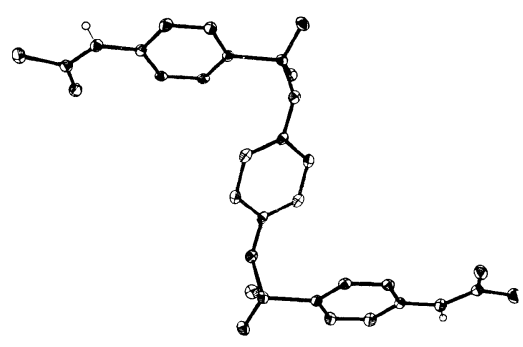

(c)
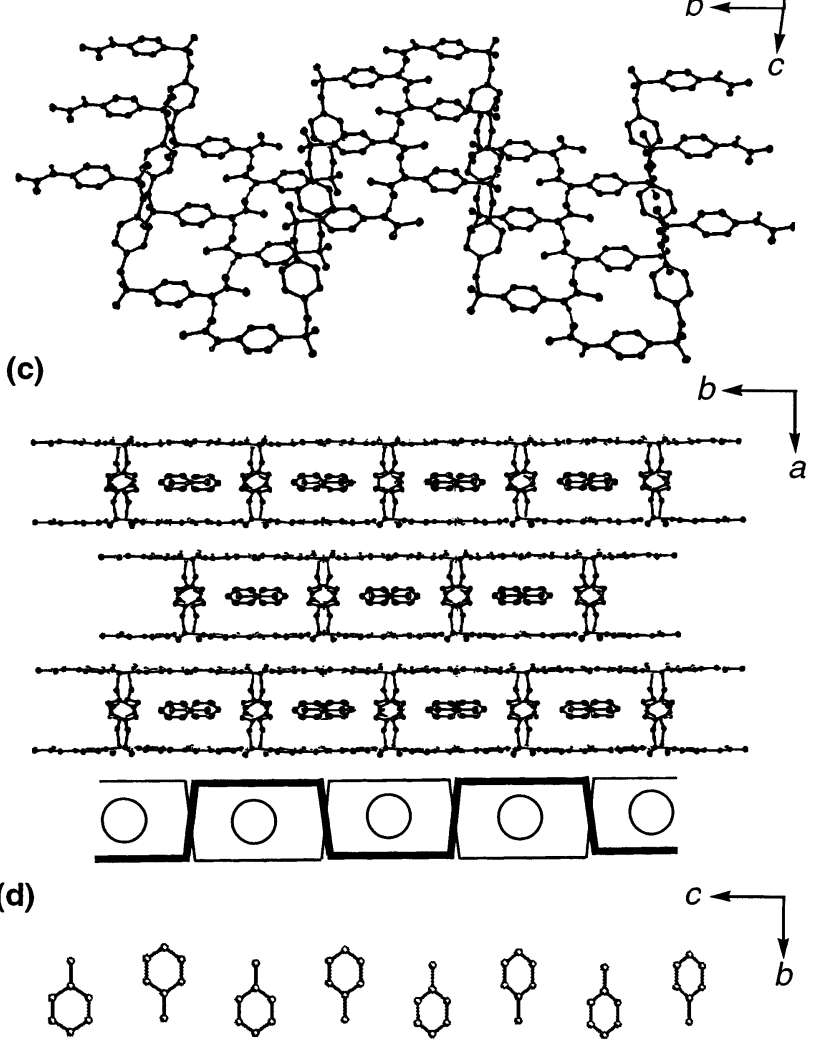

FIGURE 3. Crystal structure of 3: (a) the Z-shaped molecular conformation, (b) a square wavelike hydrogen-bonding sheet, (c) a view of crystal packing looking down the hydrogenbonding axis (c direction) with a corresponding schematic representation (the line width indicates the relative position and the circles indicate the toluene solvent molecules), and (d) the alignments of toluene solvents in the channels.

which demand a larger spacial separation. Both experimental and theoretical studies have suggested that benzene pairs favor an edge-to-face geometry. ${ }^{10}$ Although the alignment between two adjacent benzene rings in the solid state may not conform to the perfect T-shaped edgeto-face model in theoretical studies and thus an actual potential energy minimum, the attracting forces between them could still be critical in the determination of solidstate mol ecular and supramolecular structures of flexible organic molecules. ${ }^{10}$ Despite the presence of different arene-arene contact modes, the inter-ring geometries in $\mathbf{1}$ and 5-8 are similar and can be further classified as "face-tilted-T" structures ${ }^{10 a}$ having the aromatic hydrogens of the central arenes (ring $C$ ) directed over the arene face of $\mathrm{N}$-acetylsulfanilyl arms. The interacting $\mathrm{H}$-to-ring center and perpendicular distances and their offsets are also reported in Table 1. The torsional angles defined by (a)

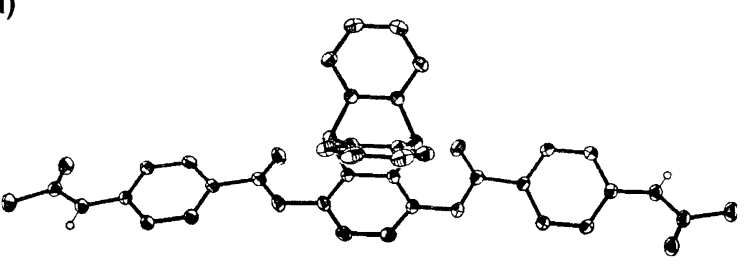

(b)
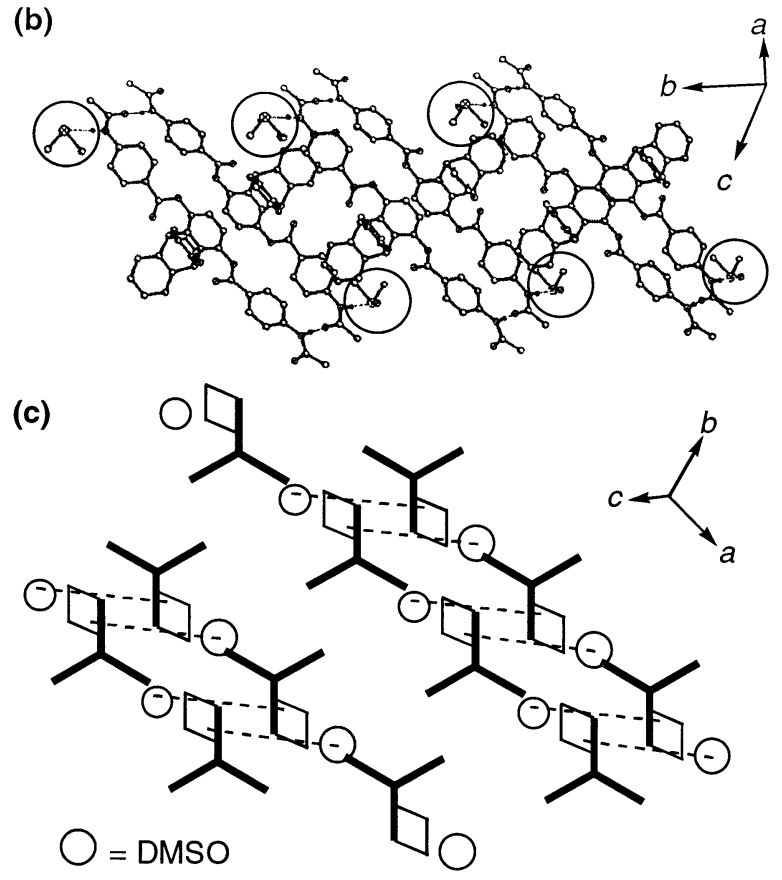

FIGURE 4. Crystal structure of 4: (a) the linear molecular conformation, (b) a view of crystal packing showing the amideamide-DMSO hydrogen-bonding motif with the DMSO molecules circled, and (c) a schematic representation of the crystal packing showing the triptycene-triptycene alignments (bold lines) and hydrogen-bonding axis (dashed lines).

$\mathrm{C}-\mathrm{O}-\mathrm{SO}_{2}-\mathrm{C}$ for $\mathbf{1}$ and $\mathbf{5}-\mathbf{8}$ are in the range of $61-75^{\circ}$, which is consistent with the preferred gauche conformation for the sulfonyl ester groups. ${ }^{11}$ The corresponding angle in the unfolded diamide $3\left(71.7^{\circ}\right)$ also falls in the range. On the other hand, the torsional angles in the less compact triptycene derivative $\mathbf{2}$ are relatively larger $\left(77.0^{\circ}\right.$ and $\left.94.1^{\circ}\right) .{ }^{16} \mathrm{~F}$ or comparison, the $\mathrm{C}-\mathrm{O}-\mathrm{CO}-\mathrm{C}$ torsional angles in 4 are $171.5^{\circ}$ and $179.1^{\circ}$, in accord with the preferred s-trans $(Z)$ conformation for the carbonyl esters. The distinct conformations between $\mathbf{1}$ and $\mathbf{4}$ demonstrate the important role of sulfonyl esters being the turn units in the folding of $\mathbf{1}$.

The heats of formation for the experimental and hypothetical conformations of $\mathbf{1}-\mathbf{8}$ have been calculated ${ }^{17}$ by using the AM 1 algorithm (Table 2). The experimental energies were obtained by using the corresponding singlecrystal molecular structures (Figures $1 a-8 a$ ) as the

(16) Although the gauche $\mathrm{C}-\mathrm{SO}_{2}-\mathrm{O}-\mathrm{C}$ conformation is preferred, the observed torsional angles in the solid state have a wide distribution. For example, out of the 44 molecules that contain one or several $\mathrm{C}_{\mathrm{Ph}}-$ $\mathrm{SO}_{2}-\mathrm{O}-\mathrm{C}_{\mathrm{Ph}}$ group(s) (85 in total) retrieved from the Cambridge Structural Database (Version 5.22, October 2001), only $27 \%$ of the groups (23/85) adopt a conformation close to a gauche form (from $45^{\circ}$ to $\left.75^{\circ}\right)$.

(17) MOPAC-AM 1 calculations were performed on a personal computer using the al gorithms supplied by the package of Quantum CAChe Release 3.2, a product of Fujitsu Limited. 
(a)

(b)
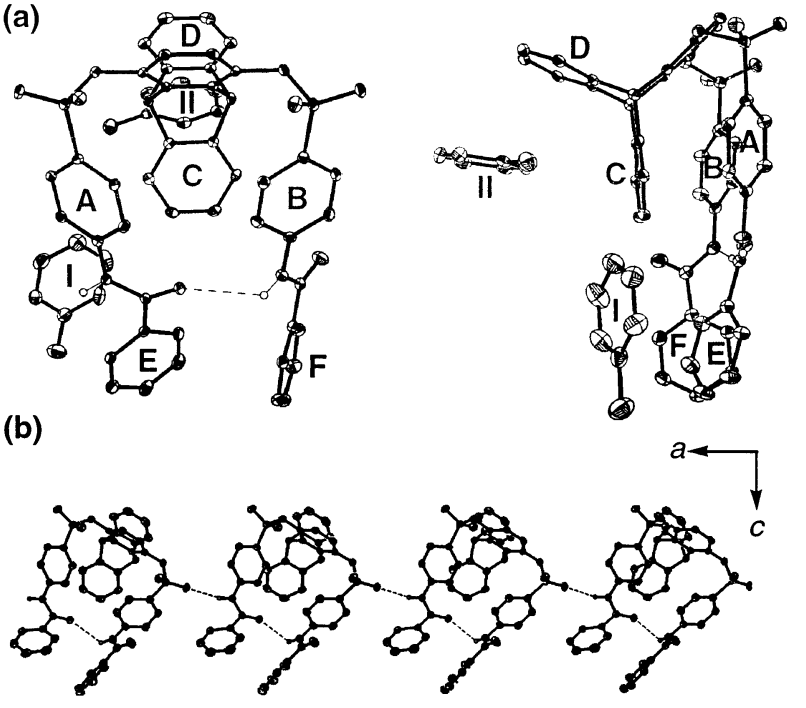

(c)

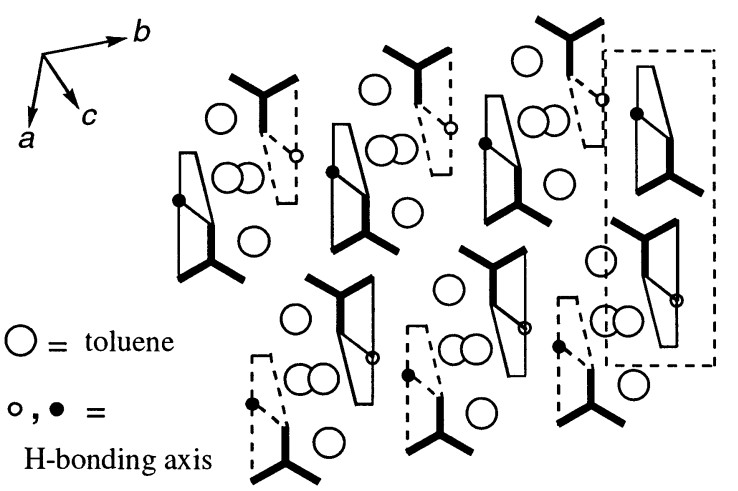

FIGURE 5. Crystal structure of 5: (a) two views of the molecular conformation, including the toluene solvent molecules, with labels on the benzene rings, (b) a hydrogenbonding chain, and (c) a schematic representation of the crystal packing looking down the hydrogen-bonding axis (void and solid circles indicate the upward $\mathrm{NH}$ and $\mathrm{CO}$ side of the amide groups, respectively) showing the triptycene-triptycene alignments (bold lines, drawings with dashed lines indicate a location of molecules in a lower plane) and supramolecular duplex (indicated by a dashed box, see text for definition).

starting points for energy minimization. The starting points for hypothetical conformations were obtained from the modification of the experimental conformations of compounds 1, 4, and $\mathbf{6}$. For example, in addition to the experimental conformation shown in Figure la, two other distinct hypothetical conformations were also investigated for $\mathbf{1}$. One hypothetical model is derived from the experimental conformation of $\mathbf{6}$ (Figure 6a) by removing the ring $C$, which retains the intramolecular amideamide hydrogen bonding but not the arene-arene contacts. The other is derived from the linear conformation of 4 (Figure $4 a$ ) by changing the carbonyl to a sulfonyl group, which exists neither hydrogen-bonding nor arenearene interactions. The first model was calculated to be higher in energy than the experimental by $2.77 \mathrm{kcal} / \mathrm{mol}$, and the conformational energy for the second model is even larger by $4.50 \mathrm{kcal} / \mathrm{mol}$. Thus, the experimental conformation for $\mathbf{1}$ is indeed a more stable one. The situation of lower conformational energy of experimental vs hypothetical is also found for the cases of $\mathbf{4}$ and $\mathbf{8}$. On the other hand, the observed conformers for 2, 3, and 5-7 (a)
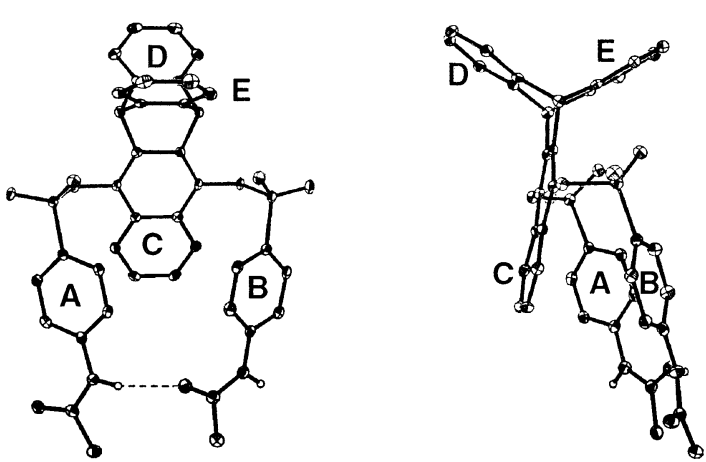

(b)

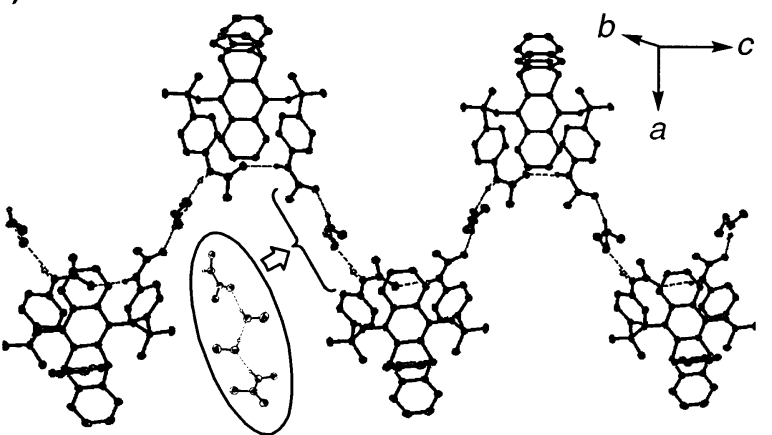

(c)

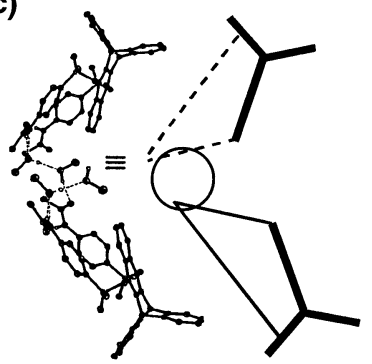

(d)

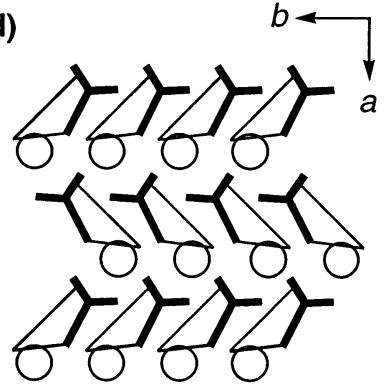

FIGURE 6. Crystal structure of 6: (a) two views of the molecular conformation with labels on the benzene rings, (b) a hydrogen-bonding chain, (c) a side view of the hydrogenbonding chain along with a corresponding schematic repre sentation, and (d) a schematic representation of the crystal packing looking down the hydrogen-bonding axis (c axis) showing the triptycene-triptycene alignments (bold lines).

are either similar to or higher in energy than the corresponding hypothetical conformers (Table 2). It should be noted that the energy between the two possible arenearene contact modes in $\mathbf{6}$ and $\mathbf{7}$ are nearly degenerate. The discrepancies between the experimental and the AM 1-suggested conformations are more pronounced in $\mathbf{2}, \mathbf{3}$, and $\mathbf{5}$. The lower energy of the hypothetical vs experimental model in $\mathbf{5}$ can be attributed to the better hydrogen-bonding geometry in the former, despite in a sacrifice of arene-arene interactions. ${ }^{18}$ While a hypothetical arene-arene contact for $\mathbf{2}$ and amide-amide hydrogen bonding for $\mathbf{3}$ can lower the heat of formation by 1.42 and $5.36 \mathrm{kcal} / \mathrm{mol}$, respectively, they were not adopted. Apparently, the amide-amide hydrogen bonding and the edge-to-face arene-arene interactions al one cannot trigger the solid-state compact folding due to the competition of intermolecular interactions. Previous ex-

(18) The $\mathrm{N}(\mathrm{H}) \cdots \mathrm{O}$ and $(\mathrm{N}) \mathrm{H} \cdots \mathrm{O}$ distances are 3.05 and $2.13 \AA$ respectively, and the $\mathrm{N}-\mathrm{H} \cdots \mathrm{O}$ and $\mathrm{H} \cdots \mathrm{O}=\mathrm{C}$ angles are $152^{\circ}$ and $145^{\circ}$ respectively, for the hypothetical conformation of $\mathbf{5}$. 
(a)

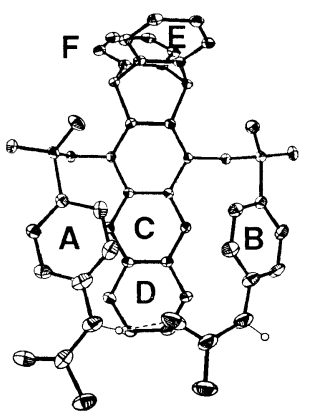

(b)

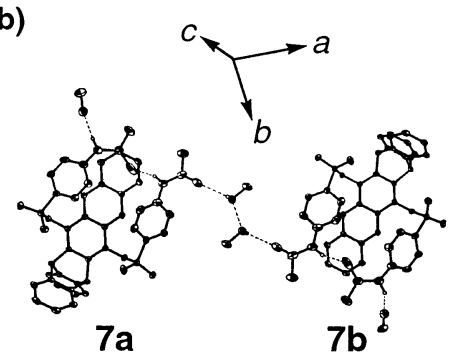

(c)

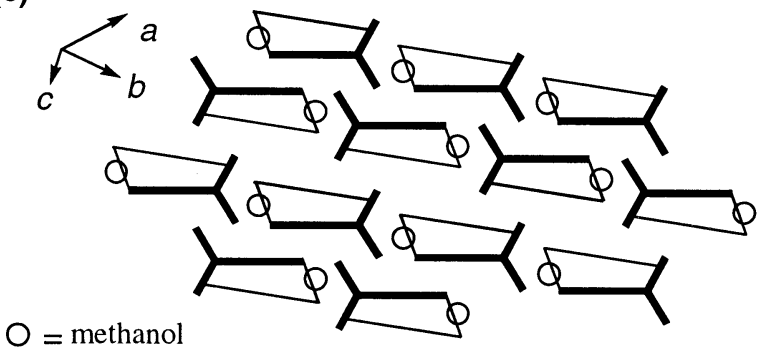

FIGURE 7. Crystal structure of 7: (a) two views of the molecular conformation (represented by conformer 7a) with labels on the benzenerings, (b) two views of a hydrogen-bonded supramolecular dimer formed by conformers $\mathbf{7 a}$ and $\mathbf{7 b}$, and (c) a schematic representation of the crystal packing looking down the hydrogen-bonding axis showing the triptycenetriptycene alignments (bold lines).

amples of molecular folding in small molecules $^{5}$ and oligomeric species ${ }^{4}$ are driven cooperatively by either multiple hydrogen bonds or extensive arene-arene stacking interactions. Thus, the cooperative effect of hydrogen bonding and edge-to-face arene-arene interactions in current systems appears to be unique.

Solution-phase conformational studies have been carried out by ${ }^{1} \mathrm{H}$ NMR spectroscopy for $\mathbf{1}$ and 3-6 in $\mathrm{CD}_{2}$ $\mathrm{Cl}_{2}$ at 295 and $223 \mathrm{~K}$. As shown in Figure 9, the amide chemical shift $(\delta \mathrm{NH})$ of $\mathbf{4}$ is upfield of the amide $\delta \mathrm{NH}$ in the others. When compared with $\mathbf{1}$, the upfield shifting of $\delta \mathrm{NH}$ in 4 is as large as $0.55 \mathrm{ppm}$ at $295 \mathrm{~K}$ and 0.92 ppm at $223 \mathrm{~K}$ (Table 3 ). In addition, the aromatic protons in 4 exhibit little changes in chemical shifts $(\Delta \delta \mathrm{CH}<$ $0.04 \mathrm{ppm}$ ) as the temperature was lowered, whereas the corresponding aromatic protons in the rings $\mathrm{A}, \mathrm{B}$, and $\mathrm{E}$ of 1 (Figure 1a) display substantial upfield chemical shifts.

Since $\delta \mathrm{NH}$ and aromatic $\delta \mathrm{CH}$ are sensitive to the group's involvement in hydrogen bonding and arenearene interactions, ${ }^{5}$ respectively, these observations not only further confirm the poor folding ability of $\mathbf{4}$ due to the preferred s-trans conformation of the carbonyl-ester (a)

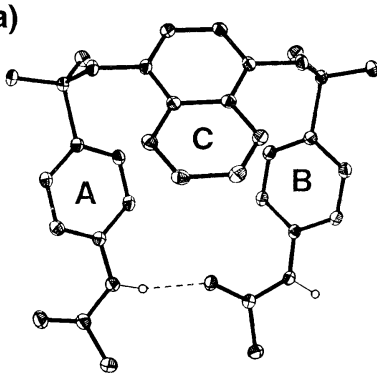

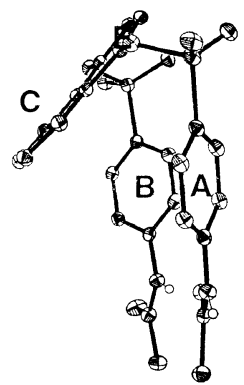

(b)

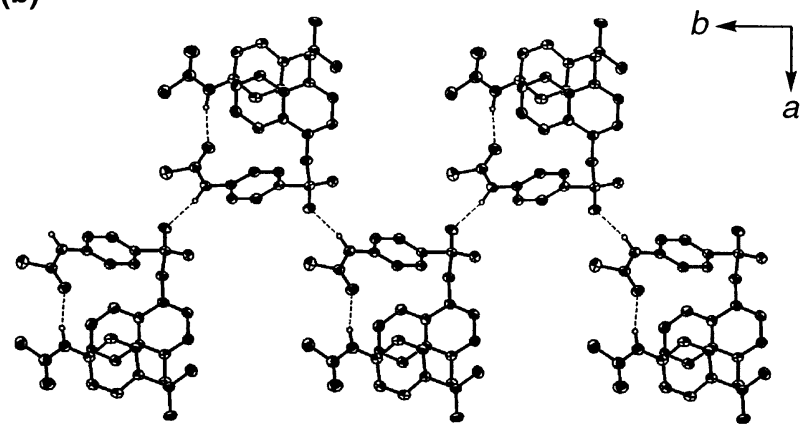

(c)

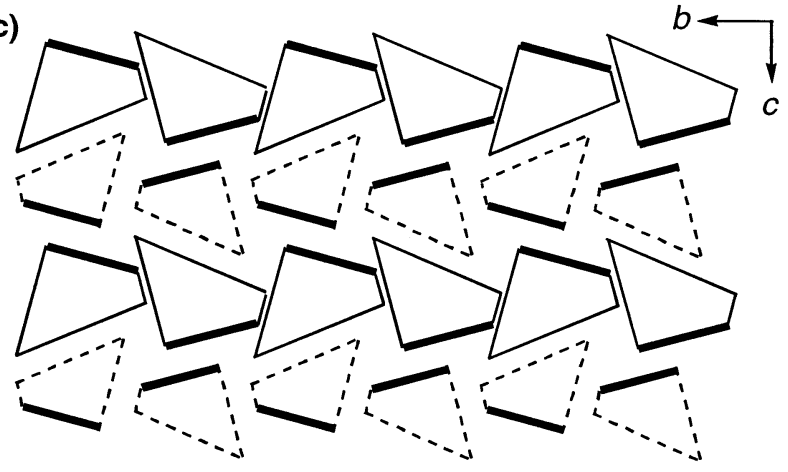

FIGURE 8. Crystal structure of 8: (a) two views of the molecular conformation with labels on the benzene rings, (b) a hydrogen-bonded chain, and (c) a schematic representation of the crystal packing looking down the a axis (perpendicular to the one-dimensional hydrogen-bonding axis), where the bold lines represent the naphthalene groups.

segments, but also suggest the existence of a rapid conformational equilibrium and an increased population of the energetically favored but entropically disfavored fol ded conformer for $\mathbf{1}$ at lower temperature. However, the large upfield shifting observed for the protons in the central ring $\mathrm{E}$ rather than the flanking rings $\mathrm{C}$ and $\mathrm{D}$ indicates that the folded conformation for $\mathbf{l}$ in $C_{2} \mathrm{Cl}_{2}$ is different from the one in the solid state. Instead, it is more like the hypothetical conformer $\mathbf{C}$, as defined in Table 2, which has the hydrogen-bonded N-acetylsulfanilyl arms oriented away from the flanking benzene rings. It thus appears that in $\mathrm{CD}_{2} \mathrm{Cl}_{2}$ the arene-arene interactions between the flanking benzene rings and the $\mathrm{N}$-acetylsulfanilyl arms are not enough to overcome the entropy loss on going form the less compact conformer $\mathbf{C}$ to the compact structure observed in the solid state. The corresponding ${ }^{1} \mathrm{H}$ NMR behavior of 3, 5, and $\mathbf{6}$ suggests that each has a folded conformer similar to that of $\mathbf{1}$ with a fol ding propensity either higher (6) or lower (3 and $\mathbf{5}$ ) than $\mathbf{1}$. Since such a folded conformation is energetically favorable according to AM 1 modeling and similar to the 
TABLE 1. Selected Intramolecular Structural Data, Including the Hydrogen-Bonding Geometry,

Arene-Arene Contact Distances and Angles, and Sulfonate Torsional Angles

\begin{tabular}{|c|c|c|c|c|c|c|}
\hline & $1 \mathrm{~m}$ & 1mt & $5^{e}$ & 6 & $7^{f}$ & 8 \\
\hline \multicolumn{7}{|c|}{ Amide-Amide Hydrogen Bonding } \\
\hline & & 2.89 & 3.25 & 2.99 & 2.60 & 2.93 \\
\hline & & & & & & 2 \\
\hline & & & & & & 1( \\
\hline H $\cdots$ & 14 & 144 & 143 & 142 & 131 & 130 \\
\hline mean deviation & 0.0500 & 0.1420 & 0.1976 & 0.0772 & 0.0900 & 0.0 \\
\hline
\end{tabular}

\begin{tabular}{|c|c|c|c|c|c|c|}
\hline \multicolumn{7}{|c|}{ Arene-Arene Contact Geometries ${ }^{a, b}$} \\
\hline$A \cdots C(\AA)^{c}$ & 4.21 & 4.42 & 4.48 & 4.25 & 4.15 & 4.63 \\
\hline H-to-centroid $(\AA)$ & 3.27 & 3.06 & 3.12 & 3.03 & 2.98 & 3.83 \\
\hline H-to-ring perp $(\AA)$ & 2.59 & 2.90 & 2.89 & 2.70 & 2.75 & 3.05 \\
\hline offset $(\AA)^{\mathrm{b}}$ & 1.99 & 0.97 & 1.39 & 1.36 & 1.33 & 2.31 \\
\hline$A \cdots C(\text { deg })^{d}$ & 27 & 34 & 36 & 41 & 35 & 50 \\
\hline$B \cdots C(\AA)^{c}$ & 4.51 & 4.26 & 4.28 & 4.28 & 4.12 & 4.70 \\
\hline H-to-centroid $(\AA)$ & 2.99 & 3.15 & 3.13 & 3.28 & 3.00 & 3.63 \\
\hline H-to-ring perp $(\AA)$ ) & 2.91 & 2.91 & 2.95 & 2.78 & 2.69 & 3.41 \\
\hline offset $(\AA)^{b}$ & 0.70 & 1.21 & 1.04 & 1.75 & 1.31 & 1.24 \\
\hline$B \cdots C(\text { deg })^{d}$ & 50 & 33 & 22 & 40 & 32 & 57 \\
\hline \multicolumn{7}{|c|}{ Sulfonate Torsional Angles } \\
\hline $\mathrm{C}-\mathrm{O}-\mathrm{SO}_{2}-\mathrm{C}(\mathrm{deg})$ & 61.4 & 66.5 & 69.1 & 72.0 & 72.5 & 9.1 \\
\hline & 66.3 & 66.7 & 72.5 & 73.4 & 74.8 & 9.4 \\
\hline
\end{tabular}

a For the phenyl ring labels, see Figures $1 \mathrm{a}-8 \mathrm{a}$. ${ }^{\mathrm{b}} \mathrm{A} \mathrm{C}-\mathrm{H}$ bond length of $0.95 \AA$ was adopted for calculations. ${ }^{c}$ Central-to-central ring distance. d Plane-to-plane dihedral angle (inter-ring angle). e The corresponding distances (angles) between rings $\mathbf{E}$ and $\mathbf{F}$, rings I and $\mathbf{E}$, and rings II and $\mathbf{D}$ are $4.66 \AA\left(47^{\circ}\right), 3.92 \AA\left(14^{\circ}\right)$, and $4.27 \AA\left(13^{\circ}\right)$, respectively. ${ }^{f}$ The corresponding distances (angles) between rings $\mathbf{A}$ and $\mathbf{D}$, and rings $\mathbf{B}$ and $\mathbf{D}$ are $4.63 \AA$ $\left(35^{\circ}\right)$, and $4.59 \AA\left(30^{\circ}\right)$, respectively.

TABLE 2. AM1-Calculated Heats of Formation (kcal/ mol) for the Experimental and Hypothetical Conformations of 1-8

\begin{tabular}{crrrrrr}
\hline compd & $\begin{array}{r}\text { experimental } \\
\text { (type) }^{\mathrm{a}}\end{array}$ & \multicolumn{2}{c}{$\begin{array}{c}\text { hypothetical 1 } \\
\text { (type) }^{\mathrm{a}}\end{array}$} & $\begin{array}{c}\text { hypothetical 2 } \\
\text { (type) }^{\mathrm{a}}\end{array}$ \\
\hline $\mathbf{1}$ & -133.62 & $\mathbf{A}$ & -130.85 & $\mathbf{C}^{\mathrm{d}}$ & -129.12 & $\mathbf{E}^{\mathrm{c}}$ \\
$\mathbf{2}$ & -67.61 & $\mathbf{F}$ & -69.03 & $\mathbf{D}^{\mathrm{b}}$ & & \\
$\mathbf{3}$ & -203.22 & $\mathbf{F}$ & -208.58 & $\mathbf{C}^{\mathrm{d}}$ & & \\
$\mathbf{4}$ & -59.79 & $\mathbf{E}$ & -51.40 & $\mathbf{A}^{\mathrm{b}}$ & & \\
$\mathbf{5}$ & -57.84 & $\mathbf{A}$ & -59.99 & $\mathbf{C}^{\mathrm{d}}$ & & \\
$\mathbf{6}$ & -108.40 & $\mathbf{B}$ & -108.95 & $\mathbf{A}^{\mathrm{b}}$ & & \\
$\mathbf{7}$ & -85.31 & $\mathbf{B}$ & -86.24 & $\mathbf{A}^{\mathrm{b}}$ & & \\
$\mathbf{8}$ & -187.57 & $\mathbf{B}$ & -184.11 & $\mathbf{C}^{\mathrm{b}}$ & &
\end{tabular}

a The description of features for each type of conformation is as follows: A: amide-amide hydrogen bonding and arene-arene contacts in mode 1 (as is represented by $\mathbf{1}$ in Figure 1a); B: amide-amide hydrogen bonding and arene-arene contacts in mode 2 (as is represented by $\mathbf{6}$ in Figure 6a); $\mathbf{C}$ : amide-amide hydrogen bonding only; $\mathbf{D}$ : arene-arene contacts in mode 1 only; E: none of hydrogen bonding and arene-arene contacts in a linear form (as is represented by $\mathbf{4}$ in Figure 4a); $\mathbf{F}$ : none of hydrogen bonding and arene-arene contacts in a bent form (as is represented by $\mathbf{2}$ in Figure 2a). ${ }^{\text {b }}$ Derived from $\mathbf{1}$. ' Derived from 4 d Derived from $\mathbf{6}$.

solid-state one for $\mathbf{6}$, the larger downfield shifting for $\delta \mathrm{NH}$ in 6 vs 1 upon cooling from 295 to $223 \mathrm{~K}$ can be expected. Along this line, the discrepancy between the gas-phase predictions and the solid-state results can account for the smaller spectral shift in $\mathbf{3}$ and $\mathbf{5}$. On the other hand, the noticeable but relatively small downfield shifting of $\delta \mathrm{NH}$ in $\mathbf{4}$ upon lowering the temperature can be attributed to intermolecular hydrogen-bonding interactions, which should be weak for secondary dicarboxamides in dilute solutions. ${ }^{19}$ Hydrogen-bond-active solvents such as DMSO and methanol should disfavor the folded conformers of
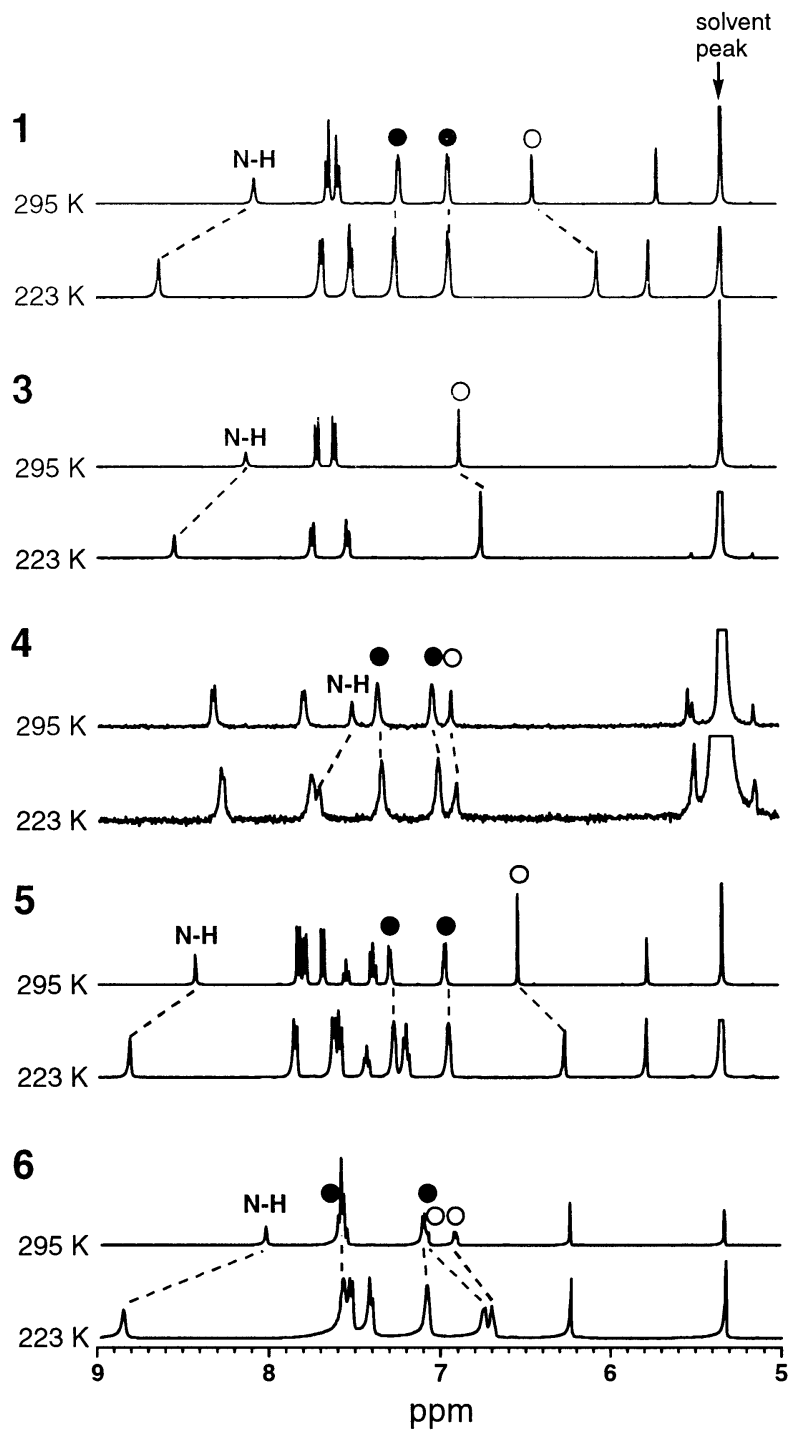

FigURE 9. ${ }^{1} \mathrm{H}$ NMR spectra (500 MHz) of $\mathbf{1}$ and 3-6 in $\mathrm{CD}_{2-}$ $\mathrm{Cl}_{2}$ at 295 and $223 \mathrm{~K}$. The substrate concentration is ca. $4 \mathrm{mM}$ expect for 4, which is $<1 \mathrm{mM}$ due to its poor solubility. The solid and void circles denote peaks due to the flanking triptycene benzene ring protons and the central arene protons, respectively.

TABLE 3. Selected ${ }^{1} H$ NMR Data for 1 and 3-6 in $\mathrm{CD}_{2} \mathrm{Cl}_{2}$ at 295 and $223 \mathrm{~K}^{\mathrm{a}}$

\begin{tabular}{cccccccc}
\hline & \multicolumn{3}{c}{$\delta \mathrm{NH}$} & & \multicolumn{3}{c}{$\delta \mathrm{CH}$ of the central arene } \\
\cline { 2 - 4 } \cline { 6 - 7 } compd & $295 \mathrm{~K}$ & $223 \mathrm{~K}$ & $\Delta \delta^{\mathrm{b}}$ & & $295 \mathrm{~K}$ & $223 \mathrm{~K}$ & $\Delta \delta^{\mathrm{b}}$ \\
\hline $\mathbf{1}$ & 8.05 & 8.61 & 0.51 & 6.43 & 6.05 & -0.38 \\
$\mathbf{3}$ & 8.10 & 8.52 & 0.42 & 6.85 & 6.73 & -0.12 \\
$\mathbf{4}$ & 7.50 & 7.70 & 0.20 & 6.92 & 6.89 & -0.03 \\
$\mathbf{5}$ & 8.41 & 8.80 & 0.39 & 6.53 & 6.26 & -0.27 \\
$\mathbf{6}$ & 8.01 & 8.84 & 0.83 & $6.91,7.08$ & $6.69,6.74$ & $-0.22,-0.34$
\end{tabular}
K).

a See the caption of Figure 9 for details. ${ }^{\mathrm{b}} \Delta \delta=\delta(295 \mathrm{~K})-\delta(223$

these diamides. Thus, the ability of $\mathbf{1}$ and $\mathbf{5}-\mathbf{8}$ to crystallize in a folded form in the presence of methanol and/or DMSO is an aspect of interest.

Crystal Packing. Acyclic secondary dicarboxamides $\mathrm{R}_{1}-\mathrm{CONH}-\mathrm{R}_{2}-\mathrm{NHCO}-\mathrm{R}_{1}$ and $\mathrm{R}_{1}-\mathrm{NHCO}-\mathrm{R}_{2}-\mathrm{CONH}-$

(19) Lewis, F. D.; Yang, J .-S.; Stern, C. L. J . Am. Chem. Soc. 1996, $118,2772-2773$

7350 J. Org. Chem., Vol. 67, No. 21, 2002 
(a)

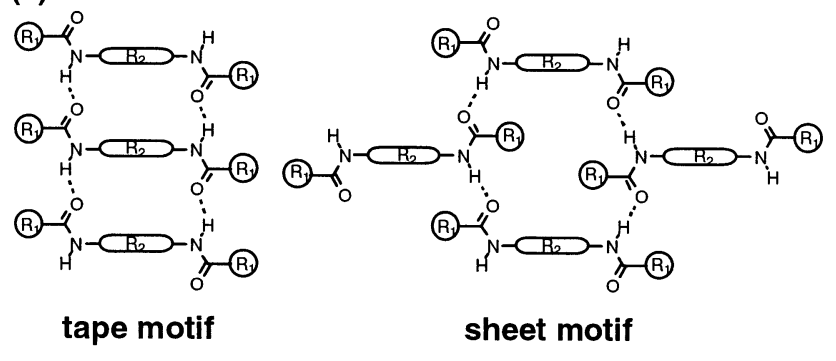

(b)
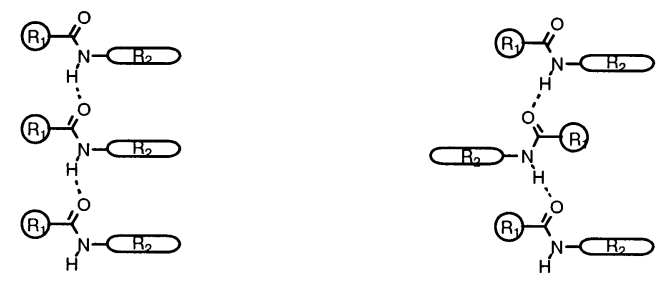

translation motif

glide or $2_{1}$-axis motif

FIGURE 10. Schematic representations of the common hydrogen-bonding motifs formed by secondary (a) diamides $\mathrm{R}_{1}-\mathrm{CONH}-\mathrm{R}_{2}-\mathrm{NHCO}-\mathrm{R}_{1}$ and (b) monoamides $\mathrm{R}_{1}-\mathrm{CONH}-$ $\mathrm{R}_{2}$.

$R_{1}$ with a linear spacer $R_{2}$ generally adopt either a tape or a sheet hydrogen-bonding motifs (Figure 10a).15,20 While the shorter intermolecular distance in a tape vs sheet motif has the advantage of stronger intermol ecular interactions, a sheet structure is more flexible in accommodating bulky $R_{1}$ or $R_{2}$ groups. I ndeed, the Z-shaped conformation of diamide $\mathbf{3}$ results in a square wavelike sheet (Figure 3b). Although a hypothetical sheet that can accommodate the bulky spacer in $\mathbf{4}$ appears to be possible, $\mathbf{4}$ adopts neither a tape nor a sheet motif. Instead, an unprecedented dimer motif is formed, where the intermolecular amide-amide hydrogen bonding is terminated by DMSO solvent molecules ${ }^{21}$ at the $\mathrm{N}-\mathrm{H}$ site of the amide group through $\mathrm{S}-\mathrm{O} \cdots \mathrm{H}-\mathrm{N}$ hydrogen bonds (Figure 4b). Selected intermolecular hydrogen-bonding data are reported in Table 4.

Because of the intramolecular amide-amide hydrogen bonding, there is only one pair of amide hydrogen-bond donor and acceptor available for intermolecular connections in $\mathbf{1}$ and $\mathbf{5 - 8}$, which resembles the condition of secondary monoamides. The packing of acyclic secondary monoamides $\mathrm{R}_{1}-\mathrm{CONH}-\mathrm{R}_{2}$ generally conforms to either one of the two hydrogen-bonding motifs (Figure 10b), translation and glide or $2_{1}$-axis related, and correlates to the tape and the sheet motifs for diamides, respectively (Figure 9a). ${ }^{15}$ I ndeed, compound $\mathbf{1}$ adopts a 2 -axis related motif in both $\mathbf{1 m}$ and $\mathbf{1} \mathbf{m t}$ (Figure $1 \mathrm{~b}$ ). A substitution of the $\mathrm{N}$-acetyl by the bulkier $\mathrm{N}$-benzoyl group leads to a translation-like packing mode for $\mathbf{5}$ (Figure 5b), where

(20) Lewis, F. D.; Yang, J .-S.; Stern, C. L. J . Am. Chem. Soc. 1996, $118,12029-12037$ and references therein.

(21) The DMSO molecules are slightly disordered in the crystal, indicating that the void space created by $\mathbf{4}$ is slightly larger than the size of DMSO. Thus, the choice of DMSO instead of methanol as the guest molecules might be related to their sizes in crystal packing. It should be noted that the unfolding of $\mathbf{4}$ is inherent as discussed in the text and should not be attributed to the interaction with DMSO. intermolecular hydrogen bonding is through the sulfonyl $\mathrm{S}=\mathrm{O}$ instead of the amide $\mathrm{C}=\mathrm{O}$. A modified $2_{1}$-axis related motif is observed for $\mathbf{6}$, where the hydrogenbonding chain is participated by two methanol molecules between the amide groups (F igure 6b). Hydrogen-bonded dimers consisting of conformers $\mathbf{7 a}$ and $\mathbf{7 b}$ are generated in the packing of $\mathbf{7}$ with the assistance of methanol molecules (Figure $7 b$ ). The hydrogen-bonding motif in $\mathbf{8}$ is also $2_{1}$-axis related (Figure $8 b$ ), but it is different from those for $\mathbf{1}$ and $\mathbf{6}$. The intramolecular amide-amide hydrogen bonds in $\mathbf{8}$ are perpendicular to the intermolecular amide-sulfonate hydrogen-bonding chain, resulting in an interesting hydrogen-bonding motif. These observations clearly suggest that, unlike the intramolecular hydrogen bonding, the intermolecular amideamide hydrogen bonding can be readily perturbed by other hydrogen-bond donors/acceptors within the solvent or molecules.

The phenomenon of triptycene-triptycene pairing is observed for all triptycene derivatives except for $\mathbf{6}$. It is interesting to note that, having nearly the same molecular (primary building block) and hydrogen-bonded chain (secondary building block) structures, crystals $\mathbf{I m}$ and lmt have different crystal packing modes (Figure 1c), particularly the inclusion of solvent molecules in the latter but not the former. While a pair of adjacent chains associated by triptycene-triptycene interactions in $\mathbf{1}$ could be described as a "supramolecular duplex", by the same token the absence of hydrogen bonding in $\mathbf{2}$ leads to "supramolecular dimers" (Figure 2b). The supramolecular dimers in $\mathbf{4}$ are constructed by both amide-amide hydrogen bonding and triptycene-triptycene interactions (Figures $4 \mathrm{~b}$ and $4 \mathrm{c}$ ). Compound 5 also form supramolecular duplexes with a packing mode similar to that of lmt, which includes solvent molecules (Figure 5c). The triptycene-triptycene interactions in $\mathbf{7}$ are more than dimeric, because each triptycene group interacts with at least two adjacent triptycene groups (Figure 7c). In conjunction with the formation of hydrogen-bonded dimers (Figure 7b), the triptycene-triptycene interactions result in "supramolecular tapes". The driving forces of the common feature of triptycene-triptycene pairing are at least 2-fold: the arene-arene interactions, including both the "offset parallel" and the "edge-tilted-T" modes, ${ }^{10 a}$ and the close packing effect. The latter is manifest, because the pairing is structurally complementary and can increase the shape compatibility between adjacent molecules. However, to achieve the purpose of triptycenetriptycene pairing and to adopt a regular hydrogenbonding motif (Figure 10) appear to be incompatible. A priority of the former might account for the various irregular intermolecular hydrogen-bonding motifs for current triptycene derivatives. Accordingly, the absence of triptycene-triptycene pairing in $\mathbf{6}$ might indicate that the observed crystal structure is al ready closely packed. Indeed, compound $\mathbf{6}$ has the highest calculated crystal density among the six triptycene derivatives in this work (see Supporting Information). The geometric data pertaining to the triptycene-triptycene interactions are reported in Table 4.

The crystal packing of the nontriptycene derivatives $\mathbf{3}$ and $\mathbf{8}$ also display interesting features. Two adjacent square wavelike sheets in $\mathbf{3}$ are interpenetrated to form solvent channels in a one-dimensional ladderlike array, 
TABLE 4. Selected Intermolecular Structural Data for the Hydrogen-Bonding Geometry and Triptycene-Triptycene Contact Distances and Angles

\begin{tabular}{|c|c|c|c|c|c|c|c|c|c|}
\hline & $1 \mathbf{m}$ & lmt & 2 & 3 & 4 & 5 & 6 & 7 & 8 \\
\hline \multicolumn{10}{|c|}{ Intermolecular $\mathrm{N}-\mathrm{H} \cdots \mathrm{OX}$ Hydrogen Bonding Geometries } \\
\hline$X=$ & $\mathrm{C}^{\mathrm{a}}$ & $\mathrm{C}^{\mathrm{a}}$ & & $\mathrm{C}^{\mathrm{a}}$ & $\begin{array}{l}\mathrm{C}^{\mathrm{a}} \\
\left(\mathrm{S}^{\mathrm{c}}\right)\end{array}$ & $\mathrm{S}^{\mathrm{b}}$ & $C^{d, e}$ & $\mathrm{C}^{\mathrm{d}, \mathrm{e}}$ & $\mathrm{S}^{\mathrm{b}}$ \\
\hline$N(H) \cdots O(\AA)$ & 2.89 & 2.92 & & 3.38 & $\begin{array}{l}2.91 \\
(2.84\end{array}$ & 3.16 & 2.94 & 3.30 & 2.94 \\
\hline$(\mathrm{N}) \mathrm{H} \cdots \mathrm{O}(\AA)$ & 1.99 & 2.04 & & 2.49 & $\begin{array}{l}2.00 \\
(1.98)\end{array}$ & 2.33 & 2.11 & 2.76 & 2.07 \\
\hline $\mathrm{N}-\mathrm{H} \cdots \mathrm{O}$ (deg) & 163 & 162 & & 160 & $\begin{array}{l}163 \\
\text { (169) }\end{array}$ & 157 & 158 & 120 & 168 \\
\hline $\mathrm{H} \cdots \mathrm{O}-\mathrm{X}(\mathrm{deg})$ & 174 & 162 & & 161 & $\begin{array}{l}157 \\
\text { (153) }\end{array}$ & 173 & 129 & 163 & 130 \\
\hline $\begin{array}{l}d_{1}(\AA)^{f} \\
d_{2}(\AA)^{f} \\
\alpha(\text { deg })^{f}\end{array}$ & $\begin{array}{l}3.38 \\
3.84 \\
60\end{array}$ & $\begin{array}{l}3.51 \\
3.88 \\
62\end{array}$ & $\begin{array}{l}\text { ycer } \\
3.25 \\
3.54 \\
69\end{array}$ & tycen & $\begin{array}{l}\text { g Geo } \\
3.81 \\
3.87 \\
59\end{array}$ & $\begin{array}{l}3.64 \\
3.85 \\
67\end{array}$ & & $\begin{array}{l}3.40 \\
3.68 \\
65\end{array}$ & \\
\hline
\end{tabular}

${ }^{a}$ Amide $(\mathrm{N}-\mathrm{H}) \cdots$ amide $(\mathrm{O}=\mathrm{C})$ hydrogen bonding. ${ }^{\mathrm{b}}$ Amide $(\mathrm{N}-\mathrm{H}) \cdots$ sulfonate $(\mathrm{O}=\mathrm{S})$ hydrogen bonding. ${ }^{\mathrm{c}} \mathrm{Amide}(\mathrm{N}-\mathrm{H}) \cdots \mathrm{DMSO}(\mathrm{O}=\mathrm{S})$ hydrogen bonding. ${ }^{d} \mathrm{Amide}(\mathrm{N}-\mathrm{H}) \cdots \mathrm{M}$ ethanol $(\mathrm{O}-\mathrm{C})$ hydrogen bonding. $\mathrm{e}$ In the presence of two other types of hydrogen bonding: (a) methanol $(\mathrm{OH}) \cdots$ amide $(\mathrm{O}=\mathrm{C})$ and $(\mathrm{b})$ methanol $(\mathrm{OH}) \cdots$ methanol $(\mathrm{O}-\mathrm{C})$ with $\mathrm{O}(\mathrm{H}) \cdots \mathrm{O}$ distances in the range of $2.72-3.12 \AA$. ${ }^{\mathrm{f}} \mathrm{The}$ definition of $d_{1}, d_{2}$, and $\alpha$ are as follows:

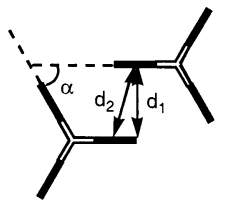

for $1,2,4$, and 5

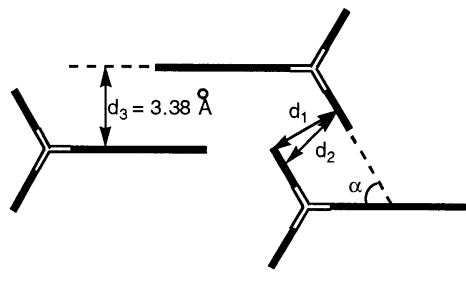

for 7 and a section view of these channel networks resembles a brick wall (a "bilayer" arrangement ${ }^{22}$ ) (Figure 3c). The interpenetration of sheets might be in part driven by the arene-arene interactions between the central benzene rings of 3. On the other hand, no specific arene-arene contacts exist in $\mathbf{8}$. Even so, it has the largest calculated crystal density among the nine crystals reported herein, indicating of a closely packed crystal (Figure 8c).

Crystals Imt and 3-7 include solvent molecules either as guests in the cavities of the network (1mt, 3, and 5) or as participants in hydrogen bonding with the building blocks (4, 6, and 7) (Figures $1 \mathrm{c}$ and 3c-7c). Crystal 1mt is the only one that includes two different solvent molecules, methanol and toluene in a 1 to 2 ratio. Since crystal $\mathbf{1 m}$ does not include solvent molecules, the presence of toluene molecules must be responsible for the solvent inclusion in $\mathbf{l m t}$. The behavior of solvent-induced cavity formation is interesting but not surprising, because the network is rich in aromatic rings, and thus the guest-host arene-arene interactions might compensate for the decreased interactions between host molecules. Indeed, Im and Imt have similar packing densities (Table 1). The inclusion of toluene molecules might be also important in the crystal formation of $\mathbf{3}$ due to the edge-to-face arene-arene interactions between toluene and 3. The arene-arene interactions between toluene and the building blocks are particularly obvious in 5, as is shown in Figure $5 \mathrm{a}$. While our results is consistent with previous observations that iptycene derivatives tend to create cavities in the condense phases due to the threedimensional rigid skeleton of the iptycene groups, ${ }^{7,23}$ the

(22) Holman, K. T.; Martin, S. M.; Parker, D. P.; Ward, M. D. J Am. Chem. Soc. 2001, 123, 4421-4431. pairing behavior of triptycene groups however reduces the chance of making cavities.

\section{Concluding Remarks}

The essential structural elements and noncovalent interactions responsible for the compact folding of $\mathbf{1}$ in the solid state are identified on the basis of our systematic crystallographic studies on compounds 1-8. While the sulfonyl ester groups function as turn units due to the allowed $\mathrm{C}-\mathrm{O}-\mathrm{SO}_{2}-\mathrm{C}$ gauche conformation, a compact molecular conformation cannot be achieved without the cooperative effect of intramolecular amide-amide hydrogen bonding and edge-to-face arene-arene interactions. Structural modifications of $\mathbf{1}$ without interfering with these three components will not perturb the compact folding, as are demonstrated by 5-8. On the other hand, structural modifications that affect any one of these essentials (e.g., 2-4) will release the compact form. It should be noted that either hydrogen bonds or arenearene interactions have been shown to be responsible for the folding of many small or oligomeric organic compounds,, 45 but examples resulting from a cooperative function of them are relatively rare.

The crystal structures of $\mathbf{1 - \mathbf { 8 }}$ demonstrate the importance of molecular shape in the determination of the solid-state supramolecular architectures of triptycene derivatives. This is manifested by the contrast between

(23) (a) Wilcox, C. F .: Roberts, F. D. J . Org. Chem. 1965, 30, 19591963. (b) Bashir-Hashemi, A.; Hart, H.; Ward, D. L. J . Am. Chem. Soc 1986, 108, 6675-6679. (c) Venugopalan, P.; Bürgi, H.-B.; Frank, N. L.; Baldridge, K. K.; Siegel, J . S. Tetradedron Lett. 1995, 36, 24192422. (d) Marc Veen, E.; Postma, P. M.; J onkman, H. T.; Spek, A. L.; Feringa, B. L. Chem. Commun. 1999, 1709-1710. 
the common feature of triptycene-triptycene pairing and the various irregular motifs for hydrogen bonding in these crystals. The triptycene-triptycene pairing between adjacent molecules not only brings about arenearene interactions but also reduce the shape irregularity of the triptycene group in favor of compact crystal packing. An immediate consequence of such a feature is the incompatibility with the regular tape (translation related) or sheet (glide or $2_{1}$-axis related) amide-amide hydrogen-bonding motifs for most of these triptycene derivatives, thus leading to the various modi fied hydrogenbonding patterns. When compared with those by rigid planar building blocks, the supramolecular structures constructed by flexible and nonplanar molecules are apparently more complicated and less predictable. However, shape irregularity has been one of the methods in producing crystalline inclusion compounds. ${ }^{24}$ Although the triptycene-triptycene pairing reduces the porosity in the crystals of triptycene derivatives, solvent channels containing toluene molecules are observed in $\mathbf{1 m t}$ and 5. Thus, the molecular folding and supramolecular packing behavior elucidated herein for 1-8 might have implications for the design of new folding systems, supramolecular architectures, and crystalline inclusion compounds.

\section{Experimental Section}

Methods. Data for all X-ray structures were collected using a Siemens SMART CCD or a Nonius Kappa CCD diffractometer with graphite-monochromated Mo K $\alpha$ radiation $(\lambda=$ $0.71073 \AA$ ) at $150 \pm 1 \mathrm{~K}$. The structures were solved by direct methods and refined by full matrix least-squares and difference F ourier techniques with SHELXTL. Empirical absorption corrections were applied with the SADABS or the SORTAV program. All non-hydrogen atoms were refined anisotropically. Hydrogen atoms were assigned idealized locations and given isotropic thermal parameters $1.2 \times$ the thermal parameter of the carbon atoms (but $1.5 \times$ for the hydrogens in methyl groups) to which they were attached. The corresponding $50 \%$ thermal ellipsoid plots are shown in Figures 1-8.

Materials. Solvents for organic synthesis were reagent grade or HPLC grade. THF was dried by sodium metal, and acetone was dried with Drierite before use. Anhydrous toluene and DMF and all other compounds were used as received. Triptycene hydroquinone $\mathbf{9}^{13}$ and the triptycene quinone precursors $\mathbf{1 2}$ and $\mathbf{1 3}^{14}$ were prepared according to the literature procedures.

1,4-Bis(arenesulfonyloxy)-9,10-dihydro-9,10[1',2']-benzenoanthracenes (1, 2, and 10). A general procedure for obtaining the crude products is illustrated by the case of $\mathbf{1}$ : a mixture of $9(0.5 \mathrm{~g}, 1.74 \mathrm{mmol}), \mathrm{N}$-acetylsulfanilyl chloride $(1.63 \mathrm{~g}, 6.10 \mathrm{mmol})$, and potassium carbonate $(0.48 \mathrm{~g}, 3.48$ $\mathrm{mmol}$ ) in $40 \mathrm{~mL}$ of anhydrous acetone was refluxed under nitrogen for 5 days. In the cases of $\mathbf{1}$ and $\mathbf{2}$, the solution was cooled and the white preci pitate (crude product) was collected. The yellowish crude product was sequentially washed with $10 \% \mathrm{Na}_{2} \mathrm{CO}_{3}, \mathrm{H}_{2} \mathrm{O}$, and $\mathrm{MeOH}$ to afford white solid with purity larger than $\mathbf{9 5 \%}$. In the case of $\mathbf{1 0}$, the solution was cooled and the preci pitate was removed. The filtrate was concentrated under reduced pressure. Methanol was then added to the residue, and the resulting white solid was collected by filtration. Further purification was performed by recrystallization in $\mathrm{MeOH} /$ toluene (for $\mathbf{1}$ and 10) or in $\mathrm{MeOH} / \mathrm{CH}_{2} \mathrm{Cl}_{2}$ (for 2). 1 (yield: 77\%; mp: $231{ }^{\circ} \mathrm{C}$ decomposed): ${ }^{1} \mathrm{H}$ NMR (DMSO- $\mathrm{d}_{6}$,

(24) Solid-State Supramolecular Chemistry: Crystal Engineering in Comprehensive Supramolecular Chemistry; MacNicol, D. D.; Toda, F .; Bishop, R.; Eds.; Pergamon: Exeter, 1996; Vol. 6.
$200 \mathrm{MHz}$ ): 2.09 (s, 6H) 5.77 (s, 2H), 6.68 (s, 2H), 6.95 (dd, J $=5.3$ and $3.2 \mathrm{~Hz}, 4 \mathrm{H}), 7.32(\mathrm{dd}, J=5.3$ and $3.2 \mathrm{~Hz}, 4 \mathrm{H}), 7.84$ $(\mathrm{s}, 8 \mathrm{H}), 10.50(\mathrm{~s}, 2 \mathrm{H}) \mathrm{ppm} ;{ }^{13} \mathrm{C}$ NMR (DMSO-d, $50 \mathrm{MHz}$ ): $24.53,47.73,119.26,120.74,124.56,125.64,127.38,130.05$, $141.24,142.31,143.88,145.55,169.72$ ppm; IR (KBr): 3310, 3267, 1682, 1593, 1534, 1369, 1172, $830 \mathrm{~cm}^{-1}$; FAB-HRMS calcd for $\mathrm{C}_{36} \mathrm{H}_{28} \mathrm{~N}_{2} \mathrm{O}_{8} \mathrm{~S}_{2}\left(\mathrm{M}^{+}\right)$680.1287, found 680.1271. 2 (yield: 75\%; mp: $231-233{ }^{\circ} \mathrm{C}$ ): ${ }^{1} \mathrm{H}$ NMR (DMSO-d, 200 $\mathrm{MHz}): 2.45(\mathrm{~s}, 6 \mathrm{H}), 5.83(\mathrm{~s}, 2 \mathrm{H}), 6.73(\mathrm{~s}, 2 \mathrm{H}), 7.04(\mathrm{dd}, \mathrm{J}=5.1$ and $3.1 \mathrm{~Hz}, 4 \mathrm{H}), 7.37(\mathrm{dd}, \mathrm{J}=5.1$ and $3.1 \mathrm{~Hz}, 4 \mathrm{H}), 7.49(\mathrm{~d}$, J $=6.8 \mathrm{~Hz}, 4 \mathrm{H}), 7.85(\mathrm{~d}, \mathrm{~J}=6.8 \mathrm{~Hz}, 4 \mathrm{H}) \mathrm{ppm} ;{ }^{13} \mathrm{C}$ NMR (DMSO$\left.\mathrm{d}_{6}, 50 \mathrm{MHz}\right): 21.48,47.67,120.66,124.56,125.63,128.58$, $130.76,131.52,141.21,142.28,143.82,146.45$ ppm; IR (KBr): 1595, 1471, 1379, 1174, $840 \mathrm{~cm}^{-1}$; FAB-HRMS calcd for $\mathrm{C}_{34} \mathrm{H}_{26} \mathrm{O}_{6} \mathrm{~S}_{2}\left(\mathrm{M}^{+}\right)$594.1171, found 594.1177. Anal. Calcd for $\mathrm{C}_{34} \mathrm{H}_{26} \mathrm{O}_{6} \mathrm{~S}_{2}:$ C, 68.67, H, 4.41. Found: C, 68.50, H, 4.51. 10 (yield: 45\%; mp: $236-238{ }^{\circ} \mathrm{C}$ ): ${ }^{1} \mathrm{H}$ NMR (DMSO-d 6,200 $\mathrm{MHz}): 5.83(\mathrm{~s}, 2 \mathrm{H}), 6.77(\mathrm{~s}, 2 \mathrm{H}), 6.97(\mathrm{dd}, \mathrm{J}=5.1$ and $3.2 \mathrm{~Hz}$, $4 \mathrm{H}), 7.36(\mathrm{dd}, \mathrm{J}=5.1$ and $3.2 \mathrm{~Hz}, 4 \mathrm{H}), 8.19(\mathrm{~d}, \mathrm{~J}=8.8 \mathrm{~Hz}$, $4 \mathrm{H}), 8.43(\mathrm{~d}, \mathrm{~J}=8.8 \mathrm{~Hz}, 4 \mathrm{H}) \mathrm{ppm} ;{ }^{13} \mathrm{C}$ NMR (DMSO- $\mathrm{d}_{6}, 50$ $\mathrm{MHz}): 47.17,120.55,124.26,125.15,125.35,130.18,139.00$, 141.18, 141.88, 143.28, 151.14 ppm; IR ( $\mathrm{KBr}):$ 1530, 1387, 1349, 1174, $845 \mathrm{~cm}^{-1}$; FAB-HRMS calcd for $\mathrm{C}_{32} \mathrm{H}_{20} \mathrm{~N}_{2} \mathrm{O}_{10} \mathrm{~S}_{2}$ $\left(\mathrm{M}^{+}\right)$656.0559, found 656.0570.

1,4-Bis(4-acetamidobenzenesulfonyloxy)benzene (3). The procedure is the same as that for the synthesis of $\mathbf{1}$ by replacing 9 with hydroquinone. 3 (yield: 69\%; mp: 195-195.5 $\left.{ }^{\circ} \mathrm{C}\right)$ : ${ }^{1} \mathrm{H}$ NMR (DMSO-d $\left.6,200 \mathrm{MHz}\right): 2.09(\mathrm{~s}, 6 \mathrm{H}), 6.98(\mathrm{~s}, 4 \mathrm{H})$, $7.68(\mathrm{~d}, \mathrm{~J}=9.0 \mathrm{~Hz}, 4 \mathrm{H}), 7.79(\mathrm{~d}, \mathrm{~J}=9.0 \mathrm{~Hz}, 4 \mathrm{H}), 10.43(\mathrm{~s}$, $2 \mathrm{H}) \mathrm{ppm} ;{ }^{13} \mathrm{C}$ NMR (DMSO-d $\left.6,50 \mathrm{MHz}\right): 24.53,118.98,124.10$, 126.98, 130.01, 145.37, 147.69, 169.72 ppm; IR (KBr): 3390, $3256,1678,1378,1154,840 \mathrm{~cm}^{-1}$; FAB-HRMS calcd for $\mathrm{C}_{22} \mathrm{H}_{21} \mathrm{~N}_{2} \mathrm{O}_{8} \mathrm{~S}_{2}\left(\mathrm{M}+\mathrm{H}^{+}\right)$505.0739, found 505.0722.

1,4-Bis(4-acetamidobenzenesulfonyloxy)-9,10-dihydro$9,10\left[1^{\prime}, 2^{\prime}\right]$ - benzenoanthracene (4). To a suspension of 4-acetamidobenzoic acid $(0.43 \mathrm{~g}, 3.67 \mathrm{mmol})$ in $15 \mathrm{~mL}$ of anhydrous THF were added DCC $(0.76 \mathrm{~g}, 3.67 \mathrm{mmol})$ and DMAP $(0.45 \mathrm{~g}, 3.67 \mathrm{mmol})$ at room temperature for $0.5 \mathrm{~h}$ before to which $9(0.30 \mathrm{~g}, 1.05 \mathrm{mmol})$ was added. The resulting mixture was stirred at room temperature overnight. The precipitate was collected and then washed with methanol to afford $0.21 \mathrm{~g}$ of white solid product. 4 (yield: $41 \%$; mp: $364.5-$ $366{ }^{\circ} \mathrm{C}$ ): ${ }^{1} \mathrm{H}$ NMR (DMSO-d $\left.6,200 \mathrm{MHz}\right): 2.15(\mathrm{~s}, 6 \mathrm{H}), 5.66(\mathrm{~s}$, 2H), 7.01 (bs, 6H), 7.42 (bs, 4H), 7.89 (d, J = $8.1 \mathrm{~Hz}, 4 \mathrm{H}), 8.25$ $(\mathrm{d}, \mathrm{J}=8.1 \mathrm{~Hz}, 4 \mathrm{H}), 10.46(\mathrm{~s}, 2 \mathrm{H}) \mathrm{ppm} ;{ }^{13} \mathrm{C}$ NMR (DMSO-d 6 , $50 \mathrm{MHz}$ ): 24.57, 47.80, 118.87, 120.42, 122.82, 124.51, 125.60, $131.47,139.41,143.42,144.49,144.89,164.46,169.45$ ppm; IR (KBr): 3367, 3337, 1739, 1704, 1682, 1370, $1269 \mathrm{~cm}^{-1}$; FAB-HRMS calcd for $\mathrm{C}_{38} \mathrm{H}_{29} \mathrm{~N}_{2} \mathrm{O}_{6}\left(\mathrm{M}+\mathrm{H}^{+}\right)$609.2025, found 609.2023.

1,4-Bis(4-aminobenzenesulfonyloxy)-9,10-dihydro-9,$10\left[1^{\prime}, \mathbf{2}^{\prime}\right]$-benzenoanthracene (11). A mixture of $\mathbf{1 0}(0.12 \mathrm{~g}$, $0.18 \mathrm{mmol})$, tin(II) chloride dihydrate $(0.41 \mathrm{~g}, 1.82 \mathrm{mmol})$ in $15 \mathrm{~mL}$ of $99.5 \% \mathrm{EtOH}$ under nitrogen was heated at $75^{\circ} \mathrm{C}$ overnight. The solution was cooled and then made slightly basic by adding $5 \% \mathrm{NaHCO}_{3}$ followed by extraction with EtOAc. The organic phase was washed with brine and dried over $\mathrm{MgSO}_{4}$. The filtrate was concentrated under reduced pressure. Methanol was then added to the residue, and the resulting white solid was collected by filtration. 11 (yield: $80 \%$; $\left.\mathrm{mp}: 241-242{ }^{\circ} \mathrm{C}\right):{ }^{1} \mathrm{H}$ NMR (DMSO-d $\left.6,200 \mathrm{MHz}\right): 5.78$ (s, $2 \mathrm{H}), 6.43(\mathrm{bs}, 4 \mathrm{H}), 6.54(\mathrm{~s}, 2 \mathrm{H}), 6.62(\mathrm{~d}, \mathrm{~J}=8.7 \mathrm{~Hz}, 4 \mathrm{H}), 7.00$ (dd, $\mathrm{J}=5.1$ and $3.1 \mathrm{~Hz}, 4 \mathrm{H}$ ), 7.37 (dd, $\mathrm{J}=5.1$ and $3.1 \mathrm{~Hz}$, $4 \mathrm{H}), 7.45(\mathrm{~d}, \mathrm{~J}=8.7 \mathrm{~Hz}, 4 \mathrm{H}) \mathrm{ppm} ;{ }^{13} \mathrm{C} \mathrm{NMR}\left(\mathrm{DMSO}^{-\mathrm{d}_{6}, 50}\right.$ $\mathrm{MHz}$ : $47.86,113.27,117.75,120.60,124.57,125.58,130.79$, $141.06,142.40,144.14,155.22$ ppm; IR (KBr): 3487, 3468, $3383,1630,1594,1165,844 \mathrm{~cm}^{-1}$; FAB-HRMS calcd for $\mathrm{C}_{32} \mathrm{H}_{24} \mathrm{~N}_{2} \mathrm{O}_{6} \mathrm{~S}_{2}:$ 596.1076, found 596.1064.

1,4-Bis(4-benzamidobenzenesulfonyloxy)-9,10-dihydro9,10[1',2]-benzeno- anthracene (5). To a solution of $\mathbf{1 1}(0.08$ $\mathrm{g}, 0.13 \mathrm{mmol}$ ) in $2 \mathrm{~mL}$ of $\mathrm{CH}_{2} \mathrm{Cl}_{2}$ were added benzoyl chloride $(0.09 \mathrm{~mL}, 0.78 \mathrm{mmol})$ and triethylamine $(0.02 \mathrm{~mL}, 1.97 \mathrm{mmol})$ 
at room temperature. The mixture was stirred overnight and then subjected to a $\mathrm{CH}_{2} \mathrm{Cl}_{2} / \mathrm{H}_{2} \mathrm{O}$ workup. The combined organic phase was washed with $5 \% \mathrm{NaHCO}_{3}$ and $\mathrm{H}_{2} \mathrm{O}$ and dried over $\mathrm{MgSO}_{4}$. The solvent was removed under reduced pressure. Methanol was then added to the residue, and the resulting white solid was collected by filtration. 5 (yield: 65\%; $\mathrm{mp}$ : 264.5-266.5 ${ }^{\circ} \mathrm{C}$ ): ${ }^{1 \mathrm{H}}$ NMR (DMSO- $\left.\mathrm{d}_{6}, 200 \mathrm{MHz}\right): 5.78(\mathrm{~s}, 2 \mathrm{H})$, $6.69(\mathrm{~s}, 2 \mathrm{H}), 6.94(\mathrm{dd}, \mathrm{J}=5.2$ and $3.1 \mathrm{~Hz}, 4 \mathrm{H}), 7.33(\mathrm{dd}, \mathrm{J}=$ 5.2 and $3.1 \mathrm{~Hz}, 4 \mathrm{H}), 7.47-7.59(\mathrm{~m}, 6 \mathrm{H}), 7.89(\mathrm{~d}, \mathrm{~J}=8.9 \mathrm{~Hz}$, $4 \mathrm{H}), 7.94(\mathrm{~d}, \mathrm{~J}=6.7 \mathrm{~Hz}, 4 \mathrm{H}), 8.06(\mathrm{~d}, \mathrm{~J}=8.9 \mathrm{~Hz}, 4 \mathrm{H}), 10.74$ (s, 2H) ppm; ${ }^{13} \mathrm{C}$ NMR (DMSO-d $6,50 \mathrm{MHz}$ ): 47.42, 114.08, $120.17,120.44,124.26,125.30,127.84,128.49,129.54,132.12$, $134.20,140.94,141.99,143.55,145.29,166.32 \mathrm{ppm}$; IR (KBr): 3393, 3330, 1672, 1520, $1170 \mathrm{~cm}^{-1}$; FAB-HRMS calcd for $\mathrm{C}_{46} \mathrm{H}_{33} \mathrm{~N}_{2} \mathrm{O}_{8} \mathrm{~S}_{2}\left(\mathrm{M}+\mathrm{H}^{+}\right)$805.1680, found 805.1670.

Triptycene Quinones 14 and 15. A general procedure is illustrated by the synthesis of $\mathbf{1 5} .^{25}$ To the solution of $\mathbf{1 3}(2.5$ $\mathrm{g}, 6.47 \mathrm{mmol}$ ) in $15 \mathrm{~mL}$ of 1,4-dioxane was added $1 \mathrm{~mL}$ of $48 \%$ $\mathrm{HBr}$. The mixture was stirred at room temperature for $1 \mathrm{~h}$. The crude product was collected by filtration and purified by column chromatography on silica gel (eluent: $\mathrm{CH}_{2} \mathrm{Cl}_{2}$ ). $\mathbf{1 4}$ (yield: 97\%; mp: $264-266{ }^{\circ} \mathrm{C}$, lit. $.^{26} \mathrm{mp}: 275-277^{\circ} \mathrm{C}$ ): ${ }^{1} \mathrm{H}$ NMR $\left(\mathrm{CDCl}_{3}, 200 \mathrm{MHz}\right): 6.00(\mathrm{~s}, 2 \mathrm{H}), 7.04(\mathrm{dd}, \mathrm{J}=5.4$ and $3.2 \mathrm{~Hz}, 4 \mathrm{H}), 7.47(\mathrm{dd}, \mathrm{J}=5.4$ and $3.2 \mathrm{~Hz}, 4 \mathrm{H}), 7.66(\mathrm{dd}, \mathrm{J}=$ 5.7 and $3.3 \mathrm{~Hz}, 2 \mathrm{H}$ ), 8.06 (dd, $\mathrm{J}=5.7$ and $3.3 \mathrm{~Hz}, 2 \mathrm{H}$ ) ppm. 15 (yield: 86\%; mp: $319-320{ }^{\circ} \mathrm{C}$ ): ${ }^{1} \mathrm{H}$ NMR $\left(\mathrm{CDCl}_{3}, 200\right.$ $\mathrm{MHz}): 6.07$ (s, 2H), 7.05 (dd, J = 5.3 and $3.2 \mathrm{~Hz}, 4 \mathrm{H}), 7.43-$ $7.51(\mathrm{~m}, 6 \mathrm{H}), 7.90(\mathrm{dd}, \mathrm{J}=6.0$ and $3.3 \mathrm{~Hz}, 2 \mathrm{H}), 8.47(\mathrm{~s}, 2 \mathrm{H})$ ppm.

Triptycene Dicarboxamides 6 and 7. A general procedure is illustrated by the synthesis of $\mathbf{6}$. To a mixture of $\mathbf{1 4}$ $(0.90 \mathrm{~g}, 0.36 \mathrm{mmol})$ and zinc powder $(0.12 \mathrm{~g}, 1.78 \mathrm{mmol})$ in 2.4 $\mathrm{mL}$ of a mixed solvent of THF/DMF $(1: 1 \mathrm{v} / \mathrm{v})$ at $0{ }^{\circ} \mathrm{C}$ under argon was added $0.36 \mathrm{~mL}$ of $\mathrm{TMSCl}$. The mixture was stirred at room temperature overnight and then decanded into ice water. The resulting crude product ( 4: 1 of 16: 14 based on ${ }^{1} \mathrm{H}$ NMR) was collected by filtration. The crude product 16 $(0.19 \mathrm{~g}, 0.39 \mathrm{mmol}), \mathrm{N}$-acetylsulfanilyl chloride $(0.37 \mathrm{~g}, 1.57$ $\mathrm{mmol})$, and potassium carbonate $(0.12 \mathrm{~g}, 0.87 \mathrm{mmol})$ in $12 \mathrm{~mL}$ of anhydrous acetone were refluxed under nitrogen for 5 days. The solution was cooled and the preci pitate was removed. The filtrate was concentrated under reduced pressure. Methanol was then added to the residue, and the resulting white solid was collected by filtration. The white sol id was then dissol ved in $\mathrm{CH}_{2} \mathrm{Cl}_{2}$ and the insol uble residue was removed by filtration. The filtrate was concentrated under reduced pressure to afford the desired compound. 6 (yield from 14: 65\%; mp: 185.5$\left.187.5^{\circ} \mathrm{C}\right):{ }^{1} \mathrm{H}$ NMR (DMSO-d $\left.\mathrm{d}_{6}, 200 \mathrm{MHz}\right): 2.15(\mathrm{~s}, 6 \mathrm{H}), 6.10$ $(\mathrm{s}, 2 \mathrm{H}), 7.10(\mathrm{dd}, \mathrm{J}=5.3$ and $3.0 \mathrm{~Hz}, 4 \mathrm{H}), 7.37(\mathrm{dd}, \mathrm{J}=5.8$ and $3.2 \mathrm{~Hz}, 2 \mathrm{H}), 7.51-7.55(\mathrm{~m}, 6 \mathrm{H}), 7.93(\mathrm{~d}, \mathrm{~J}=8.4 \mathrm{~Hz}, 4 \mathrm{H})$, $8.09(\mathrm{~d}, \mathrm{~J}=8.4 \mathrm{~Hz}, 4 \mathrm{H}), 10.59(\mathrm{~s}, 2 \mathrm{H}) \mathrm{ppm} ;{ }^{13} \mathrm{C}$ NMR (DMSO-

(25) For a different synthetic route for compound 15, see: Wasielewski, M. R.; Niemczyk, M. P.; J ohnson, D. G.; Svec, W. A.; Minsek, D. W. Tetrahedron 1989, 45, 4785-4806.

(26) Hurd, C. D.; J uel, L. H. J . Am. Chem. Soc. 1955, 77, 601-606. $\left.d_{6}, 50 \mathrm{MHz}\right)$ : 24.19, 47.92, 118.95, 121.78, 124.60, 125.76, $126.12,127.24,127.76,129.70,136.08,137.26,143.13,145.31$, 169.39 ppm; IR (KBr): 3312, 3266, 1675, 1588, 1352, 1171, $846 \mathrm{~cm}^{-1}$. FAB-HRMS calcd for $\mathrm{C}_{40} \mathrm{H}_{31} \mathrm{~N}_{2} \mathrm{O}_{8} \mathrm{~S}_{2}\left(\mathrm{M}+\mathrm{H}^{+}\right)$ 731.1522, found 731.1542. 7 (yield from 15: 27\%; $\mathrm{mp}$ : 194195. ${ }^{\circ} \mathrm{C}$ ): ${ }^{1 \mathrm{H}}$ NMR (DMSO-d $\left.6,200 \mathrm{MHz}\right): 2.08(\mathrm{~s}, 6 \mathrm{H}), 6.15$ $(\mathrm{s}, 2 \mathrm{H}), 7.16(\mathrm{dd}, \mathrm{J}=5.3$ and $3.2 \mathrm{~Hz}, 4 \mathrm{H}), 7.45(\mathrm{dd}, \mathrm{J}=6.3$ and $3.1 \mathrm{~Hz}, 2 \mathrm{H}), 7.59(\mathrm{dd}, \mathrm{J}=5.3$ and $3.2 \mathrm{~Hz}, 4 \mathrm{H}), 7.65(\mathrm{dd}$, $\mathrm{J}=6.3$ and $3.1 \mathrm{~Hz}, 2 \mathrm{H}), 7.87(\mathrm{~d}, \mathrm{~J}=8.8 \mathrm{~Hz}, 4 \mathrm{H}), 7.88(\mathrm{~s}, 2 \mathrm{H})$, $8.08(\mathrm{~d}, \mathrm{~J}=8.8 \mathrm{~Hz}, 4 \mathrm{H}), 10.52(\mathrm{~s}, 2 \mathrm{H}) \mathrm{ppm} ;{ }^{13} \mathrm{C}$ NMR (DMSO$\left.\mathrm{d}_{6}, 50 \mathrm{MHz}\right): 24.51,48.16,119.33,121.42,124.61,125.09$, $126.36,127.05,128.17,128.33,130.22,131.31,134.75,137.56$, $143.16,145.75,169.67$ ppm; IR (KBr): $3383,3282,1683,1590$, $1371,1173,768 \mathrm{~cm}^{-1}$. FAB-HRMS calcd for $\mathrm{C}_{44} \mathrm{H}_{32} \mathrm{~N}_{2} \mathrm{O}_{8} \mathrm{~S}_{2}$ $\left(\mathrm{M}^{+}\right) 780.1600$, found 780.1608 .

Compounds 8 and 18. A mixture of 1,4-naphthoquinone $(0.5 \mathrm{~g}, 3.16 \mathrm{mmol})$, zinc powder $(0.83 \mathrm{~g}, 13 \mathrm{mmol})$, and $\mathrm{N}$-acetylsulfanilyl chloride $(2.29 \mathrm{~g}, 9.80 \mathrm{mmol})$ in $4 \mathrm{~mL}$ of a THF/DMF (1: $1 \mathrm{v} / \mathrm{v})$ mixed solvent was stirred under nitrogen at room temperature overnight and then decanted into icewater. The precipitate was collected by filtration. Column chromatography using EtOAC as the eluent provided the monosubstituted compound $\mathbf{1 8}$ (45\% yield) and disubstituted compound $\mathbf{8}$ ( $10 \%$ yield). Compound $18(0.5 \mathrm{~g}, 1.39 \mathrm{mmol})$ can be further converted into compound $\mathbf{8}$ ( $75 \%$ yield) by reacting with $\mathrm{N}$-acetylsulfanilyl chloride $(0.65 \mathrm{~g}, 2.79 \mathrm{mmol})$ in the presence of $\mathrm{K}_{2} \mathrm{CO}_{3}$ under the same condition for the preparation of 1.18 (mp: $\left.192-193{ }^{\circ} \mathrm{C}\right)$ : ${ }^{1} \mathrm{H}$ NMR (DMSO-d 6,200 $\mathrm{MHz}): 2.09(\mathrm{~s}, 3 \mathrm{H}), 6.77(\mathrm{dd}, \mathrm{J}=8.2$ and $1.4 \mathrm{~Hz}, 1 \mathrm{H}), 6.98$ $(\mathrm{dd}, \mathrm{J}=8.2$ and $1.4 \mathrm{~Hz}, 1 \mathrm{H}), 7.46-7.50(\mathrm{~m}, 2 \mathrm{H}), 7.72-7.81$ $(\mathrm{m}, 5 \mathrm{H}), 8.11(\mathrm{dd}, \mathrm{J}=8.0$ and $3.8 \mathrm{~Hz}, 1 \mathrm{H}), 10.46(\mathrm{~s}, 1 \mathrm{H}), 10.51$ (s, $1 \mathrm{H}) \mathrm{ppm} ;{ }^{13} \mathrm{C}$ NMR (DMSO-d $6,50 \mathrm{MHz}$ ): 24.20, 106.71, $118.58,119.19,121.01,122.26,124.93,125.45,127.03,127.56$, $127.62,129.71,139.61,144.79,152.29,169.32 \mathrm{ppm}$; IR (KBr): 3333, 3092, 1678, 1358, 1169, $836 \mathrm{~cm}^{-1}$; FAB-HRMS calcd for $\mathrm{C}_{18} \mathrm{H}_{15} \mathrm{NO}_{5} \mathrm{~S}\left(\mathrm{M}^{+}\right) 357.0671$, found 357.0668. $8(\mathrm{mp}: 197-$ 198.5 ${ }^{\circ} \mathrm{C}$ ): ${ }^{1} \mathrm{H}$ NMR (DMSO-d $\left.6,200 \mathrm{MHz}\right): 2.09(\mathrm{~s}, 6 \mathrm{H}), 7.23$ (bs, 2H), 7.58 (bs, 2H), 7.82 (bs, 10H), 10.48 (s, 2H) ppm; ${ }^{13} \mathrm{C}$ NMR (DMSO-d $6,50 \mathrm{MHz}$ ): 24.54, 118.72, 119.03, 121.89, $127.30,127.88,128.30,130.10,143.63,145.46,169.72$ ppm; IR (KBr): 3347, 1689, 1381, 1176, $832 \mathrm{~cm}^{-1} ; \mathrm{FAB}-\mathrm{HRMS}$ calcd for $\mathrm{C}_{26} \mathrm{H}_{23} \mathrm{~N}_{2} \mathrm{O}_{8} \mathrm{~S}_{2}\left(\mathrm{M}+\mathrm{H}^{+}\right)$555.0869, found 555.0879.

Acknowledgment. We thank the National Science Council of Taiwan, ROC, for financial support, and Professor S.-M. Peng (NTU) for assistance in X-ray crystallography.

Supporting Information Available: Crystal and structure refinement data, Cartesian coordinates of AM 1-optimized structures, and ${ }^{13} \mathrm{C}$ NMR spectra (PDF) and X-ray experimental details (CIF). This material is available free of charge via the Internet at http://pubs.cas.org.

J O025758A 